Journal of

Sedimentary

Journal of Sedimentary Research, 2011, v. 81, 0-0

Current Ripples

Research

DOI: $10.2110 /$ jsr.2011.69

\title{
EVIDENCE OF BEDFORM SUPERIMPOSITION AND FLOW UNSTEADINESS IN UNIT-BAR DEPOSITS, SOUTH SASKATCHEWAN RIVER, CANADA
}

\author{
ARNOLD J.H. REESINK ${ }^{1}$ AND JOHN S. BRIDGE ${ }^{2}$ \\ ${ }^{1}$ School of Environment and Technology, University of Brighton, B2N 4GJ, Brighton U.K \\ ${ }^{2}$ Department of Geological Sciences, Binghamton University, Binghamton, New York 13902-6000, U.S.A
}

\begin{abstract}
Unit-bar deposits are ubiquitous components of river-channel deposits and strongly influence their hydrological properties, yet they are not easy to interpret. This paper concerns details of the internal structures of six unit bars from the South Saskatchewan River, Canada, that were investigated using trenches, epoxy resin peels, and $900 \mathrm{MHz}$ ground-penetrating radar (GPR) profiles. The composition of unit bars depends on flow unsteadiness and superimposed bedforms. Flow unsteadiness causes changes in the mean grain size of the sediment in transport, but is expressed primarily as a change in the type and direction of migration of smaller ripple- and dune-scale bedforms superimposed on unit bars. Superimposed bedforms with heights that exceed $25 \%$ of the host bedform height reduce their host's slope and generate inclined sets. Host bedforms with smaller superimposed bedforms form angle-of-repose cross strata with a visible pre-sorting pattern. The relationship between the formative host- and superimposed bedforms and such pre-sorted cross strata can be used to interpret numerous aspects of the three-dimensional geometries of the bedforms. Such detailed interpretations rely on: (i) regularly spaced finegrained drapes deposited during the passage of troughs of superimposed bedforms, (ii) grain-size sorting patterns generated by sorting within the superimposed bedforms before deposition, (iii) grain-size sorting during deposition by grainfall and intermittent grainflows down the bar lee-slope, and (iv) the presence and nature of low-angle reactivation surfaces.

The detailed interpretations revealed that the deposits of dam-related floods were significantly smaller than the deposits of individual unit bars in this study. The unsteady flow and sediment transport conditions are reflected by changes in the structural composition of the unit bars. Reactivation surfaces associated with flow unsteadiness, as opposed to those formed by large superimposed bedforms, were characterized by changes in mean grain size, the buildup of sediment at the base of the bar lee slope, and changes in structures formed by superimposed bedforms. Reactivation surfaces generated by large superimposed bedforms indicate that bedform preservation is likely increased in areas of flow deceleration. The trough deposits of exposed unit bars contained bubble sand, planar laminae due to upper-stage plane beds, and low-angle inclined laminae due to antidunes. These structures indicate that unit-bar troughs can act as ephemeral channels. The composition of the investigated unit bars thus emphasizes the interplay between flow unsteadiness and bed morphology in the formation of sedimentary structures in river channels.

Sediment surfaces generate visible GPR reflections where the thickness and contrast in electrical properties of the sediment layers are sufficiently large. Most cross-stratified sets were represented only by reflections from the base of the set, and not by high-angle inclined reflections from the cross strata. The local absence of reflections from cross strata is attributed to the lack of contrast in electrical properties of the well-sorted cross strata and their limited thickness relative to the radar wavelength. In contrast to cross strata, reactivation surfaces formed by large superimposed bedforms and flow unsteadiness were commonly associated with distinct inclined reflections.
\end{abstract}

INTRODUCTION

This paper examines the effects of bedform superimposition and flow unsteadiness on the internal structures of unit bars in the South Saskatchewan River near Outlook and in the Centre Angling River near Cumberland House, Saskatchewan, Canada (Fig. 1). Unit bars are lobate bedforms with lengths that are proportional to the flow width and heights that can approach bankfull depth (Bridge 2003). Their abundance and composition are known to vary, and they are found in both braided and meandering rivers (Collinson 1970; Smith 1974; Jackson 1976; Levey 1978; Blodgett and Stanley 1980; Ethridge et al. 1999; Lunt et al. 2004; Sambrook Smith et al. 2006; Reesink and Bridge 2007). Unit bars are distinguished from compound bars (mid-channel bars, point bars) by being solitary depositional units. Thus, the definition of unit bars used here does not carry a genetic interpretation as is the case for, e.g., free bars (Seminara and Tubino 1989; Tubino et al. 1999). In view of their large size, unit bars commonly persist through several floods following their formation and thus provide a record of flow unsteadiness. The large scale of the unit bars is also reflected in the large lateral extent of unit-bar sets relative to smaller bedforms (i.e., dunes). Preserved unit-bar deposits are of great importance for flow of water, oil, and contaminants through river-channel deposits because of their large lateral extent and the presence of extensive high-permeability layers (e.g., angle-of-repose cross strata) and low-permeability layers (e.g., bottomsets and fine-grained 

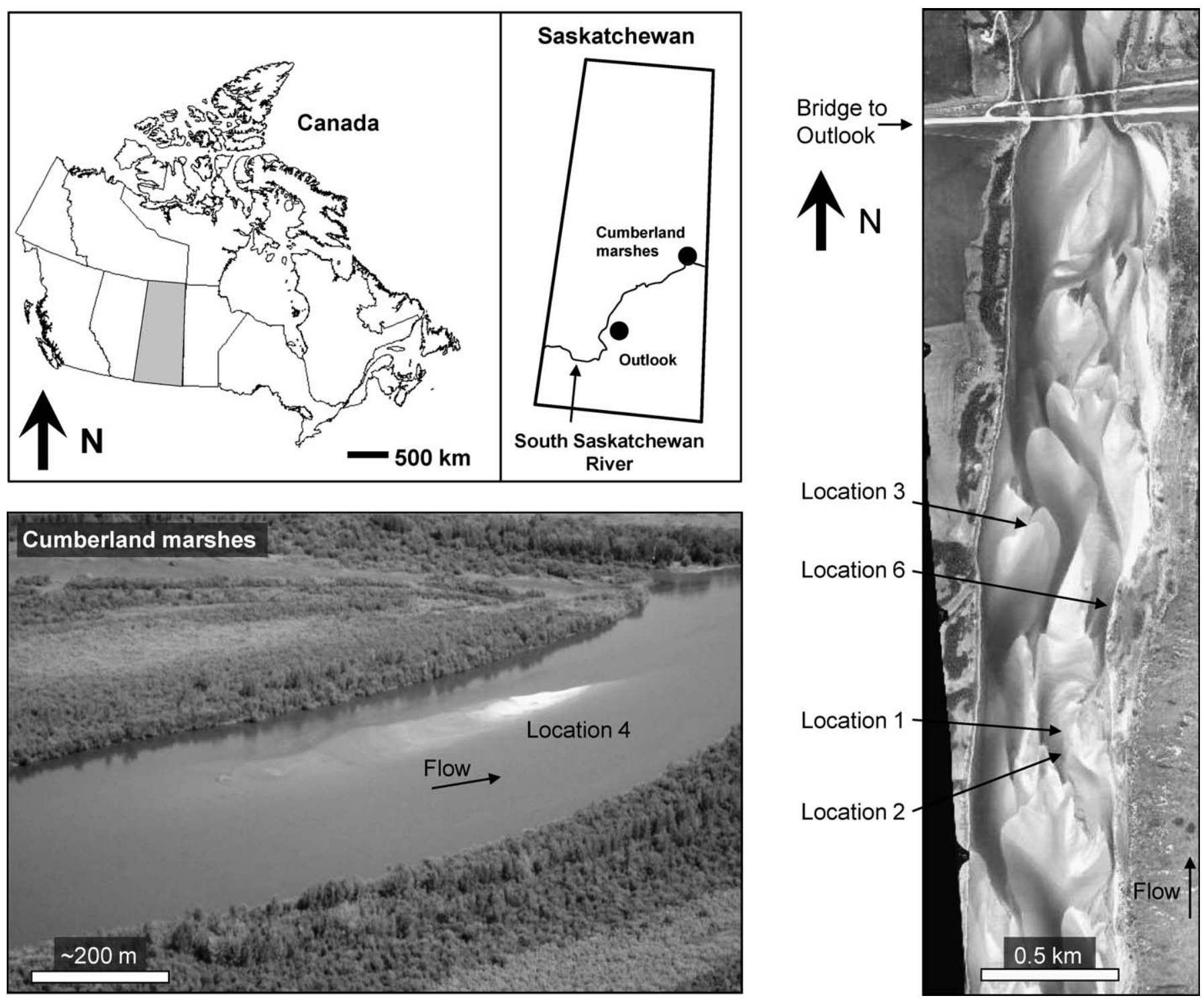

FIG. 1.-Locations of the field sites. Cumberland Marshes photo courtesy of I. Bos. Outlook photo courtesy of G. Sambrook Smith and the South Saskatchewan River project.

reactivation surfaces). Excellent descriptions of various aspects of bar deposits are available from both the rock record (e.g., Allen 1974; McCabe 1977; Allen 1983; Rust 1984; Røe and Hermansen 1993; Miall 1996; Martinius et al. 2002) and modern deposits (e.g., Boersma et al. 1968; Collinson 1970; Williams 1971; Cant and Walker 1978; Best et al. 2006; Sambrook Smith et al. 2006; Sambrook Smith et al. 2009). These studies indicate that relative abundance and composition of unit-bar deposits can vary dramatically. This complexity and a lack of systematic studies promotes confusion about the roles and relative importance of boundary conditions and formative mechanics, which consequently hinders further development of the increasing number of successful modeling studies (e.g., Tubino et al. 1999; Lanzoni 2000; Knaapen et al 2001; Federici and Seminara 2003, 2006; Nicholas 2010). This study systematically relates unit-bar composition to experimentally established processes and as such provides a foundation for further studies of unit bars and river-channel deposits.

\section{Cross Strata and Cross-Stratified Sets}

This field study follows on recent detailed experimental investigations (Reesink and Bridge 2007, 2009) and provides numerous examples of how such experimental process sedimentology can be used in practice to improve interpretations of natural channel deposits. The experiments indicate that the geometry and grain-size sorting of cross strata in unit bars is determined partly by the flow and sediment transport conditions on the back of the unit bar and hence superimposed bedform type, and partly by the relative height of the host and superimposed bedforms and hence the relative importance of grainfall and turbulence on the lee slope (Fig. 2; Jopling 1965; Allen 1982; Kleinhans 2004; Reesink and Bridge 2007, 2009). Superimposed bedforms (i.e., ripples, dunes, bedload sheets) on unit bars are ubiquitous and are composed of size-sorted sediment. These bedforms migrate faster than the unit bar on which they are developed and therefore eventually overtake it. A reactivation surface 


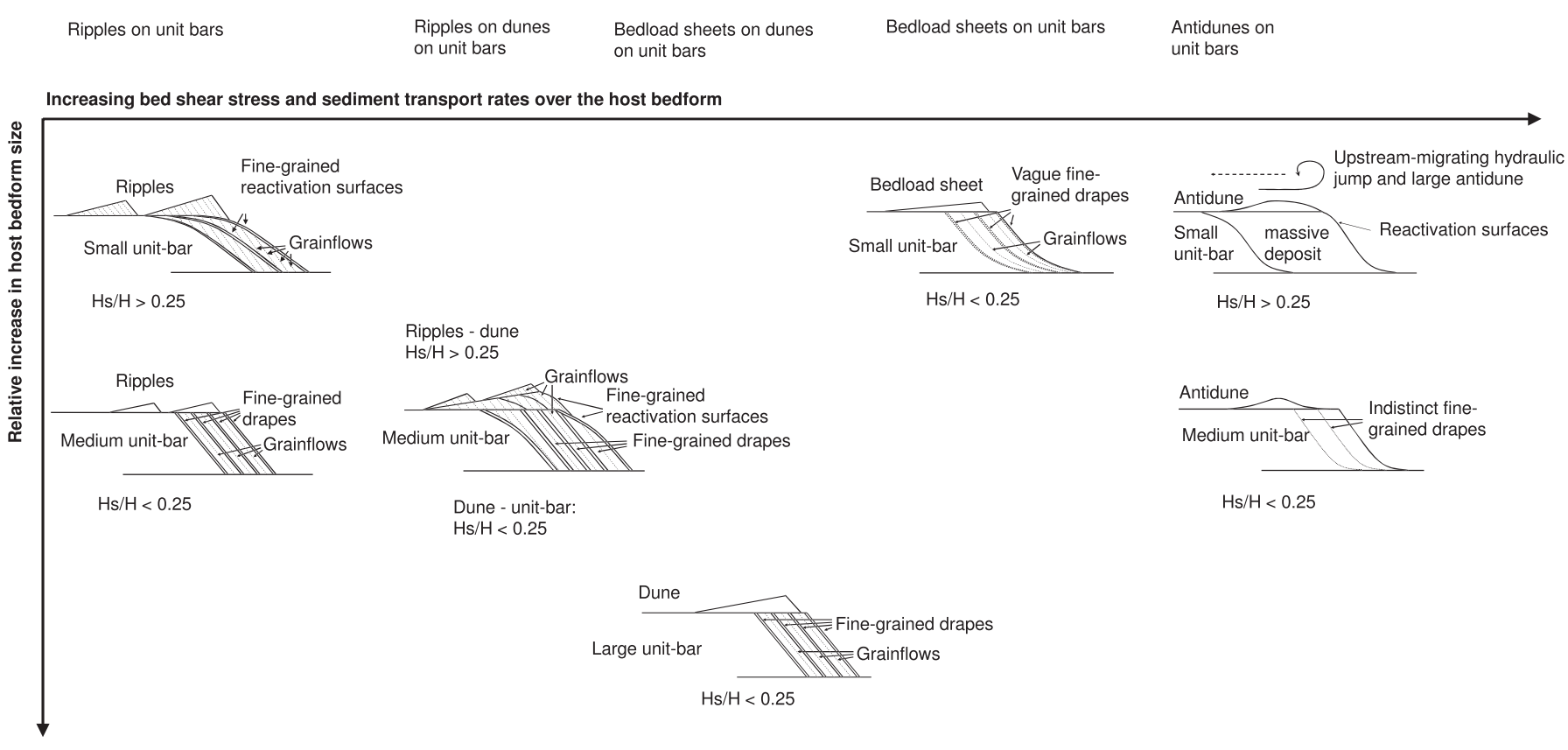

FIG. 2.-Variation in shapes and sorting patterns of cross strata as a function of superimposed bedform type and host bedform height (from Reesink and Bridge 2009). The sorting patterns of the host cross strata reflects the pre-sorting by episodically passing superimposed bedforms and re-sorting during deposition on the host lee slope.

that is lined with fine-grained sediment is formed when the height of the overtaking bedform $(H s)$ exceeds roughly $25 \%$ of its host height $(H$; Reesink and Bridge 2009). This low-angle reactivation surface forms by the erosion of the host slope during the passage of the reattachment zone of the overtaking bedform (increased turbulence and downward-directed shear stress at the downstream end of the separated flow vortex (McCabe and Jones 1977; Rubin and Hunter 1982; Fernandez et al. 2006; Reesink and Bridge 2009)). However, if an overtaking superimposed bedform has a relatively small height $(H s / H< \pm 0.25)$, the lee side of the host bedform remains at the angle of repose (Smith 1972; McCabe and Jones 1977; Rust 1984). Little bedload material is deposited on the host lee slope during the passage of the reattachment zone of small overtaking bedforms. Instead, a thin drape of finer-grained sediment is deposited on the host lee slope. The passage of the overtaking bedform itself deposits coarser bedload material on the host lee slope. The cross-sectional area of completely preserved coarse strata (delineated by fine-grained drapes) equals the cross-sectional area of the formative superimposed bedforms (Reesink and Bridge 2007, 2009). The depositional processes on the host lee slope (i.e., grainfall, grainflows, sediment transport by turbulence and shear) resort the sediment that is being deposited (and which is pre-sorted). This deposition on the lee slope thus determines the shape of the host cross strata (typically angular or tangential). The grain-size sorting patterns generated by pre-sorting and re-sorting during deposition are superimposed on one another. The extent to which the grain-size sorting patterns can be used to improve interpretations of dunes and unit-bar deposits has never been tested systematically in the field. This paper presents the first systematic investigation of cross-strata types in natural river-channel deposits.

\section{Ground-Penetrating Radar (GPR)}

Our understanding of river deposits and their 3D architecture has improved significantly over the past two decades (Hickin 1993; Miall 1996; Bridge 2003), and this progress has been made possible in no small amount by the use of GPR (Bridge 2009). The ability of GPR to image internal sedimentary structures depends on the scale and contrast in electrical properties of the sediment from which the structures are composed and the nature of the overlying and adjacent sediment (Jol and Bristow 2003; Neal 2004; Baker et al. 2007). The effect of such variables on the visibility of sedimentary structures in GPR images is still relatively poorly known. This paper therefore presents the results of GPR surveys in association with the structures of the investigated unit-bar deposits.

\section{Field Site}

This paper presents detailed analyses of the internal structures of several unit bars. The field sites (Fig. 1) were chosen based on differences in types of exposed bedforms in order to try to maximize the range of formative conditions and sedimentary structures. The field sites include unit bars with ripples (location 1), unit bars with dunes (location 2-5), deposits of unit-bar troughs that serve as ephemeral channels during low flow stage (location 5), and an overbank splay deposit (location 6). Location 5 was investigated in 2006 and is located near locations 1 and 2. Continued migration of the sand bars in 2007 caused the abandonment of this site, which consequently is not seen in Figure 1.

The main field site is located a few kilometers upstream from Outlook, Saskatchewan, Canada (Fig. 1), and is several kilometers long. In this reach, the South Saskatchewan River is a sandy braided river with a mean grain size of $0.3 \mathrm{~mm}$ (medium sand) and little silt and clay. The sediment in the thalweg is composed of coarse sand to gravel with isolated boulders or cobbles. The river flows through a terraced valley 600 to $1000 \mathrm{~m}$ wide near Outlook and has a discontinuous floodplain in the study area.

The discharge of the South Saskatchewan River at the field site is controlled by the Gardiner dam, which is located approximately $25 \mathrm{~km}$ upstream. Bar-covering discharge is approximately $280 \mathrm{~m}^{3} / \mathrm{s}$, and bankfull discharge (inundating the floodplains) is approximately $1240 \mathrm{~m}^{3} / \mathrm{s}$ (Thomas 2006). The mean annual discharge is $203 \mathrm{~m}^{3} / \mathrm{s}$, and daily variation in discharge associated with daily changes in the demand for electricity is commonly on the order of tens of cubic meters per second.

The daily variation in water and associated sediment discharge is reflected in a daily change in the exposure of unit-bar tops. During low- 
flow stages, unit bars commonly change the direction of the flow because they form obstructions to the flow. Unit-bar troughs commonly serve as channels. The unit bars in the South Saskatchewan River are on the order of tens to hundreds of meters in length and width and range in height from decimeters to meters. Dunes, ripples, and bedload sheets superimposed on the unit bars are ubiquitous. Unit bars were observed to migrate downstream during the fieldwork period, and migration rates varied from several centimeters to 1.5 meter for one flood that raised the water $0.5 \mathrm{~m}$ above a unit bar of $0.3 \mathrm{~m}$ high (see Results).

The South Saskatchewan River was studied in detail in the 1970s (Cant 1978; Cant and Walker 1978) and was recently the subject of a large research project involving coring, $200 \mathrm{MHz}$ GPR, differential GPS surveys, and time-series analysis of aerial photographs and the digital elevation models derived from them (Woodward et al. 2003; Sambrook Smith et al. 2005; Best et al. 2006; Sambrook Smith et al. 2006; Lane et al. 2010; Sambrook Smith et al. 2010; Ashworth et al. in press). The slope heights of ripples, dunes, and unit bars ranged between 0.005 and $0.3 \mathrm{~m}$ in this study, and this is the same as the slope heights in recent flume experiments on the formation of cross strata (bedform slope heights of 0.005-0.25 m; Reesink and Bridge 2007, 2009). Both the river sediments (mean size $0.3 \mathrm{~mm}$ ) and the experimental sediments $(0.4 \mathrm{~mm})$ are medium sand. Comparison of the structures observed in the field and those from the experiments is therefore very reasonable.

A second field site was investigated in a wide part (former lake) of the Centre Angling River near Cumberland House, Saskatchewan (Fig. 1). The Centre Angling River is a meandering distributary of the South Saskatchewan River in the Cumberland Marshes area (Smith et al. 1998; Farrell 2001). The investigated unit bar was located on a mid-channel bar that is attributed to the expansion of the flow when it enters the former lake bed. The unit bar was composed of medium to fine sand and had dunes with superimposed ripples exposed on its upper surface. The discharge and stage in the Centre Angling River are also controlled by an upstream dam, which causes daily variations in discharge and stage. The daily variation in stage was approximately $0.1 \mathrm{~m}$ during the investigation. The unit bar at this location is included in this investigation because it further illustrates variability in types and styles of lateral-accretion surfaces and cross strata.

\section{METHODS}

The field sites were chosen based on differences in types of exposed ripples and/or dunes in order to maximize the range of investigated internal structures. The heights and lengths of the exposed dunes and ripples were measured in the field. Changes in bed morphology of the field sites during inundation by floods were described. The placement of the investigated sites was determined using aerial photographs, which were taken shortly before the fieldwork. Bar migration rates were measures using stakes placed at the base of the bar lee slope.

\section{Ground-Penetrating Radar (GPR)}

GPR profiles were collected over the investigation sites at the location of the trenches using a PulseEKKO 1000 system with a central antenna frequency of $900 \mathrm{MHz}$. Antennae with a $900 \mathrm{MHz}$ central frequency normally have a minimum vertical resolution of tens of millimeters when used on saturated (radar velocity $\sim 0.05 \mathrm{~m} / \mathrm{ns}$; Woodward et al. 2003) or damp sands (radar velocity $\sim 0.1 \mathrm{~m} / \mathrm{ns}$; Jol and Bristow 2003; Neal 2004). Maximum vertical resolutions achieved in this study are in the order of $25 \mathrm{~mm}$. Depths of penetration were in the order of $0.5-1 \mathrm{~m}$, considerably less than the $\sim 3 \mathrm{~m}$ achieved using $200 \mathrm{MHz}$ antennae in the same sediment (Sambrook Smith et al. 2006). Processing of the GPR data involved bandpass filtering of the traces and application of an automatic gain control function using Seismic Un*x (Stockwell and Cohen 2008).

\section{Epoxy Peels}

Twenty-four epoxy peels representing a total length of approximately 30 meters were made from trench faces using epoxy resin and hardener. Most trenches were dug perpendicular to the bar front to provide an along-flow profile because this facilitates comparison to recent flume experiments (Reesink and Bridge 2007, 2009). The trench faces were planed off and covered with a mesh or cheese cloth, and the epoxy resin was carefully brushed onto the surface (following the methodology of Bouma 1979). The penetration of epoxy resin is influenced by the water content of the sediment (Reesink and Bridge 2009). When epoxy peels were made of dry sediment, epoxy penetrated the farthest down through thin, fine-grained layers adjacent to coarser-grained sediment and fully coated the grains. Conversely, when the epoxy was applied on wet sediment, the depth of epoxy penetration was directly related to grain size, and fine-grained layers had the least amount of penetration of epoxy and grains were not fully coated by epoxy resin. The differences in epoxy penetration in sediments with different water contents are attributed to capillary forces. For the peels made of trenches with a vertical variation in water content, this means that the relation between grain size and epoxyresin penetration can vary along the height of the profile. Cross-strata thicknesses were measured from the epoxy peels in a perpendicular direction. The thinnest structures that can realistically be measured from epoxy peels are in the order of 1 millimeter thick, which may be thicker than the thinnest sedimentary structures in the sediment.

\section{Classification of Primary Sedimentary Structures in Unit Bars Cross-Stratified Sets}

The sedimentary structures are generally classified based on the dimensions and geometries of both the cross strata and the sets in which they are grouped (McKee and Weir 1953; Allen 1982; Pettijohn et al. 1987; Rubin 1987; Bridge 1993a; Miall 1995). Cross-stratified sets are classified here as small-scale, medium-scale, and large-scale sets to match their vertical thicknesses to that of their formative bedforms: ripples, dunes, and (unit) bars (cf. Bridge 2003). These set scales do not directly imply a genetic origin. Overlap exists in the thicknesses of sets formed by different bedform types. Set thicknesses are therefore presented in histograms where possible. Bimodal distributions of set thicknesses shown in these indicate an origin from two different bedform types, each mode representing one bedform type.

\section{Cross Strata}

The naturally occurring cross-strata sorting patterns are readily observed and can be grouped into thick or thin strata. Stratal thickness is measured perpendicular to the plane of the cross-strata sorting (Reesink and Bridge 2007, 2009). Thin cross strata are formed by grainflow, grainfall, and reworking by turbulence and bear no evidence of larger-scale pre-sorting mechanisms. The term "thick cross strata" is used here to denote the presence of an additional, larger-scale sorting pattern such as is typically formed by superimposed bedforms (Reesink and Bridge 2007, 2009). The identification of cross strata formed by superimposed bedforms relies on the identification of: (1) occasional truncation of cross strata within the cross set by (partial) reactivation surfaces (indicating $H s / H>0.25$ ), (2) fine-grained drapes associated with the passage of superimposed bedform troughs, which delineate (3) thicker, coarser-grained strata of which the internal sorting patterns reflect the sorting within the formative superimposed bedforms (Fig. 2; Smith 1972; Rust 1984). In addition, (4) the thicker coarse strata are almost always internally composed of (vague) thinner cross strata formed due to re-sorting (e.g., grainflows) during deposition on the lee slope (Reesink and Bridge 2009) such that they occasionally appear as bundles of thinner strata. If the cross-sectional area of the superimposed bedform 
is smaller or the same as the cross-sectional area of an individual grainflow, the pre-sorting associated with the superimposed bedform is lost during redistribution of the sediment by the grainflow. The crosssectional area of fully preserved cross strata formed by superimposed bedforms equals the cross-sectional area of the formative superimposed bedforms. Cross strata formed by superimposed bedforms can therefore be used to approximate the size of the formative superimposed bedforms using the following relationship (Reesink and Bridge 2007):

$$
A=H_{s} L_{s} / 2=H \operatorname{th} / \sin \alpha
$$

in which $A$ is the along-flow cross-sectional area of the cross strata and superimposed bedforms, $H_{s}$ and $L_{s}$ are the height and length of the superimposed bedforms, respectively, $H$ is the height of the host bedform, th is the thickness of the cross strata, and $\alpha$ is the slope of the lee side of the host bedform.

The criteria for the identification of cross strata in epoxy peels were: (1) grain-size variations and (2) the depth of penetration of the epoxy resin. The accuracy of these measurements is $\pm 1 \mathrm{~mm}$. The identification of different scales of cross strata and sets results in several different classes of sedimentary structures, which were identified in the epoxy peels (Table 1). The identification sorting patterns was locally complicated by secondary structures such as bubble sand and deformation. Bubble sand forms by entrapment of air under saturated sediment and is characterized by the presence of bubbles of air in the sand. The formation of bubble sand and is attributed to relatively rapid inundation of dry sand (De Boer 1979). Such rapid inundation of dry sand frequently happens where waves run onto beaches and during initial overflowing of bars during rising river stages. The deformation can be caused by liquefaction and bioturbation (Bridge and Demicco 2008). The occurrence of bioturbation was observed in the field when the hoofs of cows investigating the field activities deformed the top of the sand bar. The original primary structures could still be discerned despite locally being overprinted by such secondary deformation structures. Bubble sand and deformation structures are also commonly observed in Van der Staaij cores, but it is not certain whether these are original structures or whether these were formed during the coring process and subsequent transportation from the field.

\section{RESULTS}

\section{UNIT BARS WITH SUPERIMPOSED RIPPLES}

\section{Location 1}

Location 1 was chosen because deflation of the top of the unit bars had exposed the tops of thick cross strata that extended laterally for several meters (Fig 3). The fine-grained layers contained more interstitial water, and this decreased wind erosion relative to the drier surrounding sediment such that they were distinctly visible on the deflated surface. Low-angle planar drapes of wind-blown sand formed in the lee of the unit bar. Although the entire unit bar migrated downstream, the investigated unitbar lee slope at location 1 migrated across the river (lateral accretion). Thus, the main direction of migration of the unit-bar slope at location 1, indicated by the dip of the cross strata, was west-to-east. Exposed ripples were measured in nearby locations because the superimposed bedforms and topsets of the unit bar were eroded. Exposed ripples were primarily sinuous crested, although straight-crested and linguoid ripples were also observed. Ripple heights and lengths were respectively $18( \pm 6) \mathrm{mm}$ and $145( \pm 36) \mathrm{mm}$ and were found to be relatively consistent throughout the study locality. Average lateral extents of exposed ripples in the area varied between 0.4 and 1.4 meters but exceeded $4 \mathrm{~m}$ in several cases.

\section{Internal Structures}

The unit-bar deposit at location 1 is composed on two sequential largescale sets that are eroded at the top and underlain by finer-grained bottomsets (Fig. 4). The sorting patterns and geometries of the cross strata vary both between and within these sets (Fig. 5). The thin, angle-ofrepose cross strata in set $1(H: 0.12-0.18 \mathrm{~m})$ at the upstream end of the unit-bar deposit are delineated by fine-grained drapes and irregularly spaces $(5.1( \pm 1.6) \mathrm{mm}$, bimodal distribution; Figs. 5A, 6A). Small-scale sets are locally found interbedded with these angle-of-repose strata (cf. Williams 1971, p. 30). Set 1 is underlain by (fully preserved) climbing return-flow ripple sets. The downstream end of set 1 gradually changes into increasingly low-angle surfaces with small-scale trough cross-strata sets (Fig. 5B). This gradual change from angle-of-repose strata to a co-set of small-scale sets is associated with a gradual change in the direction of migration of the ripples (cf. Collinson 1970). The co-set is overlain by thin low-angle drapes of sand that interfinger with the overlying set 2. Set 2 is a large-scale set $(H: 0.12-0.16)$ of angle-of-repose cross strata (Figs. 5CD). The upstream part of set 2 is composed of uniformly sorted, thin, angular cross strata that have no visible superimposed sorting pattern $(4.3( \pm 1.3) \mathrm{mm}$; Figs. $5 \mathrm{C}, 6 \mathrm{D})$. Approximately one meter farther downstream, the cross strata in set 2 change in character. The downstream part of set 2 is composed of 128 regularly spaced, thick (13.4 $( \pm 2.7) \mathrm{mm}$, Fig. 6F) coarse-grained strata that are delineated by distinct fine-grained drapes (Fig. 5D). The coarse-grained bodies display a largerscale coarsening-outward sorting and a faint, thin internal layering $(\sim 5 \mathrm{~mm}$; Fig. 6E). The thick strata vary along the set in their internal grain-size contrasts and are in places interrupted by distinct drapes of fine-grained sediment and organic material (Fig. 4, panels 5 and 6). These fine-grained reactivation surfaces typically thicken towards the stratal base where interbedded small-scale sets are locally found, and can be traced into the bottomsets of set 2. The thick cross strata directly underneath these organic layers are more poorly developed and locally overprinted by bubble sand. Set 2 terminates in low-angle drapes of windblown sand (Figs. 4, 5E) of which the development was observed in the field. Set 1, set 2, and their associated bottomsets overlie small-scale trough cross-stratified sets that are in places poorly visible because of bubble sand.

\section{Interpretation}

The stratal sorting patterns in set 1 and the older and younger parts of set 2 are distinctly different. Although the entire unit bar builds out in an across-river direction, the (varying) local formative flow direction is such that the older parts can be interpreted as upstream and the younger parts as downstream. This ambiguity between flow direction and preserved stratal orientation illustrates the naturally occurring complexity that hinders analyses of paleo-flow direction (Smith 1972). The differences in sorting and geometry of the large-scale cross strata and the context with their surrounding structures can be used to interpret details such as hostbedform height and the formative superimposed bedforms, hence flow and sediment transport conditions. The sequential occurrence of different types of structures can be used to interpret the temporal evolution of the bar.

\section{Angle of Repose Cross Strata in Set 1}

The fine-grained drapes that delineate the coarser strata in set 1 , the interbedded small-scale trough cross strata, and the gradual downstream change of set 1 to a co-set of small-scale sets all suggest that ripples were superimposed on the unit bar at the time of formation. However, the thickness of the cross strata $(5.1( \pm 1.6) \mathrm{mm})$ is comparable to that of grainflows in medium sand $(5-8 \mathrm{~mm}$; Reesink and Bridge 2007, 2009) and these strata therefore cannot be used for a reliable interpretation of formative superimposed bedforms. The fine-grained drapes and the climbing return-flow ripples of set 1 indicate high rates of settling from suspension relative to the migration rates of the bar slope and ripples in the trough (Figs. 4, 5A). 
TABLE 1.-Overview of characteristic strata observed in the unit bars with examples from the epoxy peels. This table does not provide an exhaustive overview of all possible structures and sorting patterns. ${ }^{* 1}$ Bridge $2003,{ }^{* 2}$ De Raff et al. 1977; ${ }^{* 3}$ Best and Bridge 1992; ${ }^{* 4}$ Alexander et al. 2001; ${ }^{* 5}$ Reesink and Bridge 2007, 2009; ${ }^{* 6}$ De Boer 1979 . Hs is the superimposed bedform height, $H$ is the host bedform height.

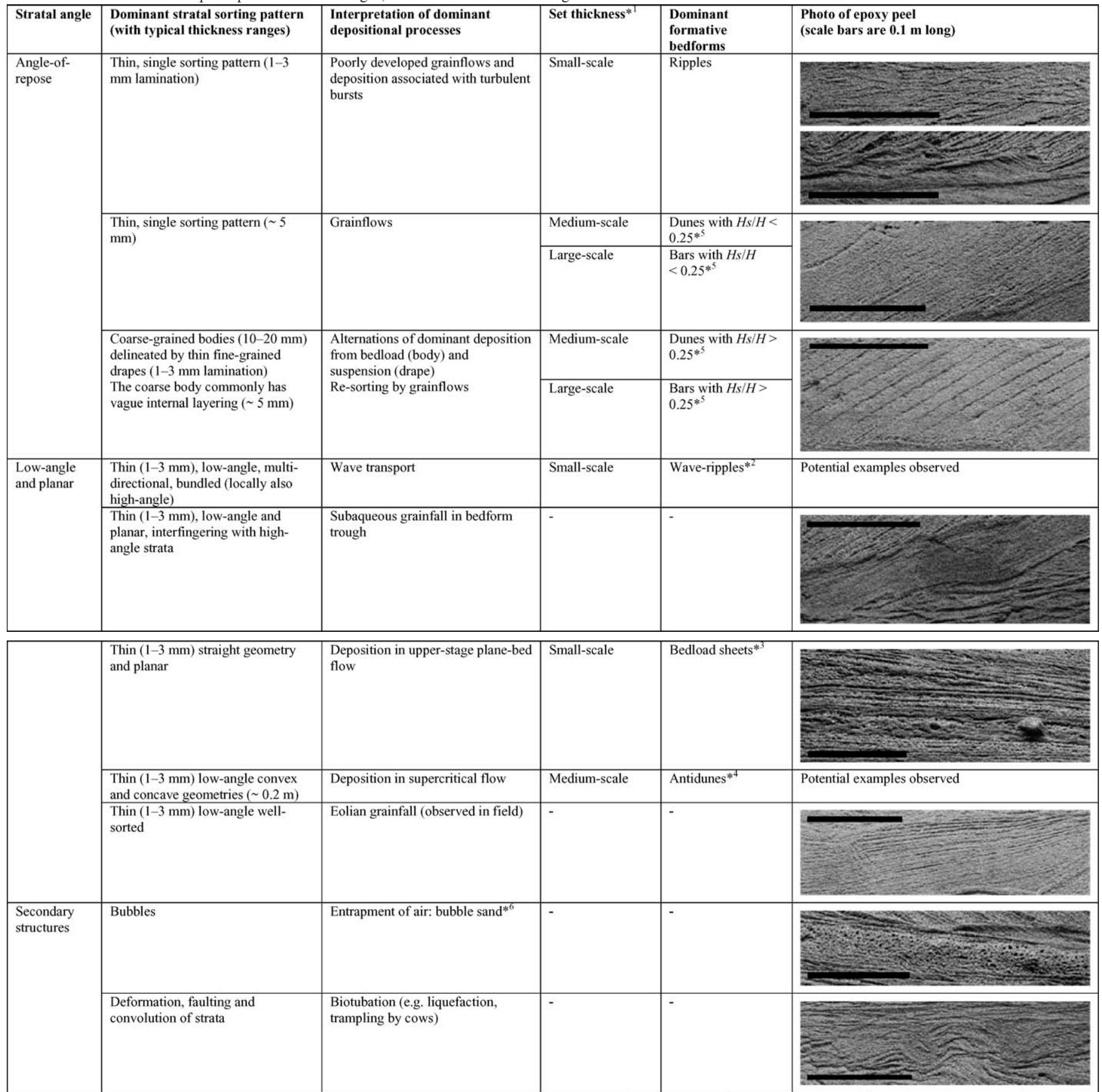

This table does not provide an exhaustive overview of all possible structures and sorting patterns. ${ }^{1}$ Bridge $2003, *^{2}$ De Raff et al. $1977 ; *^{3}$ Best and Bridge $1992 ; *^{4} \mathrm{Alexander}$ et al. 2001; $*^{5}$ Reesink and Bridge 2007, 2009; ${ }^{6}$ De Boer 1979. $H s$ is the superimposed bedform height, $H$ is the host bedform height.

\section{Change from Angle-of-Repose Cross Strata in Set 1 to Small-Scale Sets}

The direction of ripple migration changes from across-slope (dominantly formed by the return flow in the lee of the bar) to along-slope (down-river) where set 1 changes to low-angle co-set of small-scale sets. This gradual change in set orientation indicates a gradual change in flow direction from cross-slope and cross-river to along-slope and down-river (Fig. 5B). The separated flow in the lee of a superimposed bedform is expected to reduce the host's lee slope only when its height $(H s)$ exceeds $25 \%$ of the host height ( $H$; Reesink and Bridge 2007, 2009). The height of set 1 ranges between 0.18 and $0.12 \mathrm{~m}$. The height of the formative superimposed ripples can be approximated from the thicknesses of smallscale sets on the low-angle surfaces assuming that the preserved sets are approximately a third of the original ripple height (yields an average ripple height of $19( \pm 9) \mathrm{mm}$; Bridge 1997; Leclair et al. 1997; Storms et al. 1999; Leclair 2000; Leclair and Bridge 2001; Leclair 2002) and through 
A
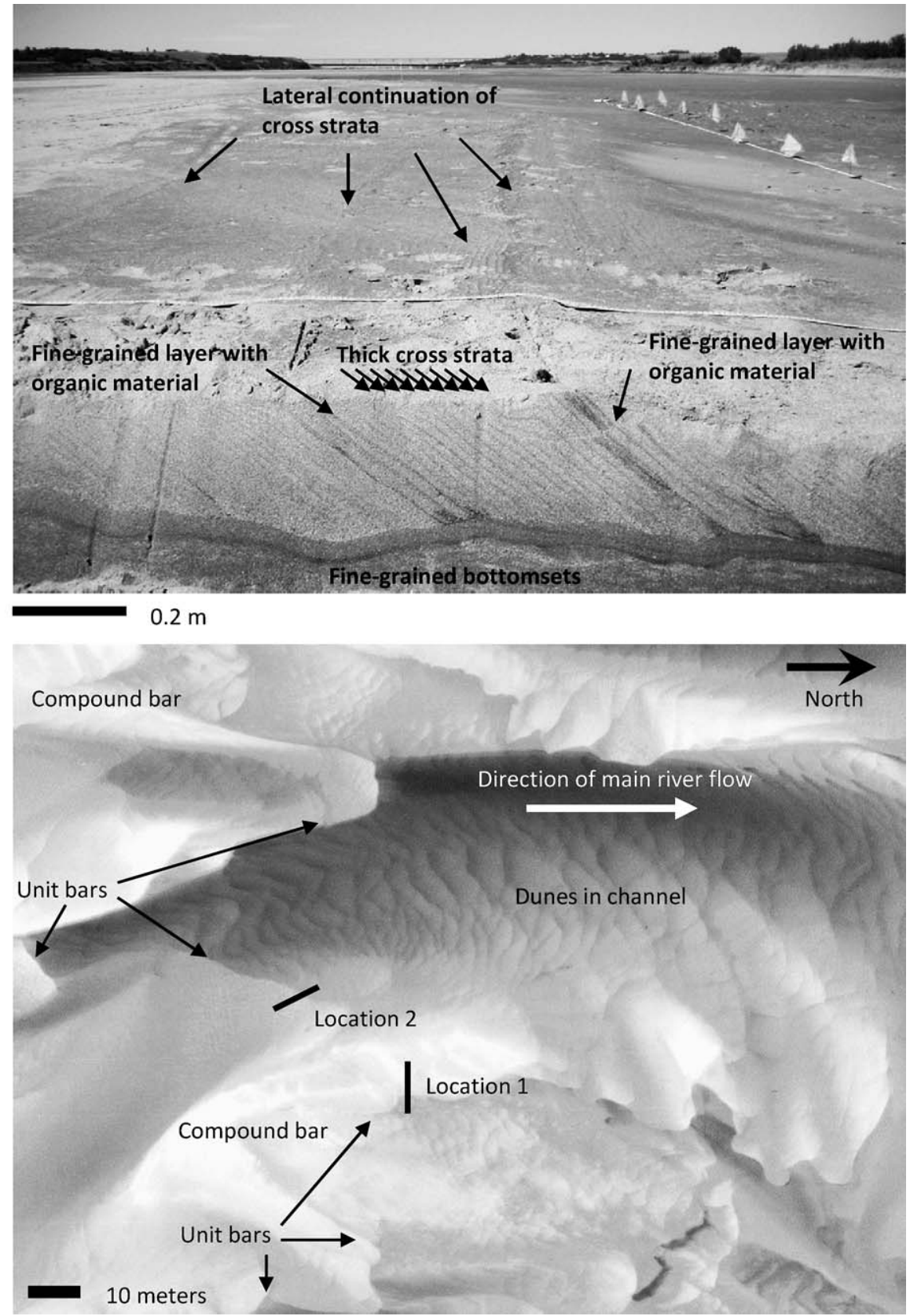

FIG. 3.-A) Field and B) aerial photograph of location 1. View of field photograph is in downstream direction. The investigated lee slope is oriented in the downstream direction, hence aggrading in the cross-stream direction. Note the large lateral extent of the cross strata exposed in the trench. direct measurements of ripple heights in the area (average ripple height 18 ( \pm 6$) \mathrm{mm}$ ). The superimposed ripples $(\sim 18 \mathrm{~mm})$ are only $10-15 \%$ of the height of the bar ( 180-120 $\mathrm{mm})$ and hence are not expected to reduce the bar lee slope. Thus, the reduction of the bar slope is related to a change in direction, not to superimposed bedforms. Such change in flow direction is commonly observed during changes in stage because bar troughs tend to steer and channelize the flow at lower flow stages.

\section{Fine-Grained Trough Deposits Associated with Set 2}

The small-scale sets are overlain by a layer of fine-grained drapes that form the bottomsets of, and interfinger with, the angle-of-repose cross strata of set 2 (Figs. 4, 5C,D). The formation of these drapes is attributed to settling from suspension. The lack of small-scale cross stratification in these bottomsets indicates lower-stage plane beds were prevalent in the bar trough during the formation of set 2 . Some of the drapes in bottomsets can be traced diagonally across the bottomsets from the base of the cross strata to the base of the bottomsets along lengths of 0.15 to $1 \mathrm{~m}$. These drapes indicate that settling in the unit-bar trough occurred in a zone with a downstream length ranging from 0.15 to 1 meter.

\section{Thin Cross Strata in the Upstream Part of Set 2}

The cross strata in the upstream section of set 2 are typical for grainflows in medium sand: thin $(4.3( \pm 1.3))$, uniformly sorted, angular, cross strata (Figs. 5C, 7D; 5-8 mm in Reesink and Bridge 2007, 2009). These thicknesses also match the thicknesses of cross strata associated with grainflows elsewhere in the unit-bar deposits (Fig. 6A, B, E, H). The lack of fine-grained drapes delineating the cross strata indicates that oversteepening and failure in the form of grainflows occurred rapidly and little time was available for the buildup of fine-grained material on the slope. The lack of evidence of pre-sorting by superimposed bedforms in 
A

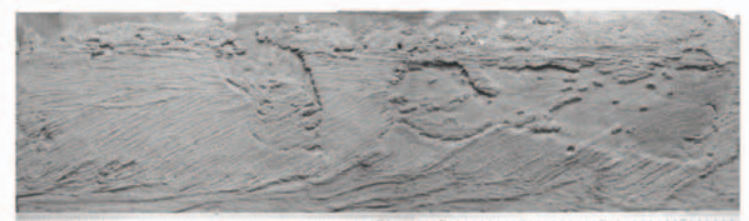

Panel 1

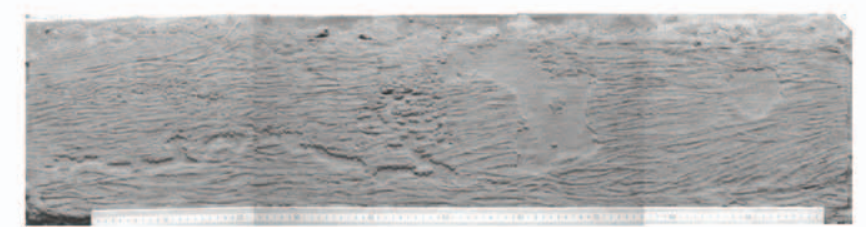

Panel 2

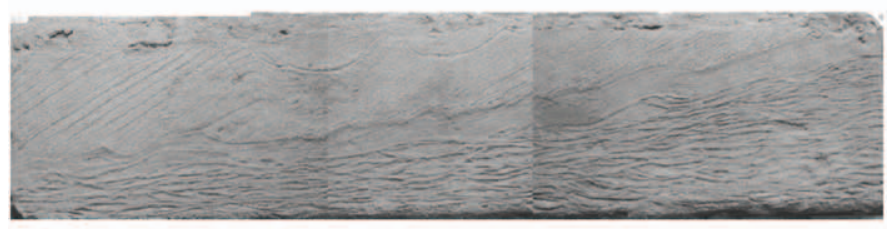

Panel 3

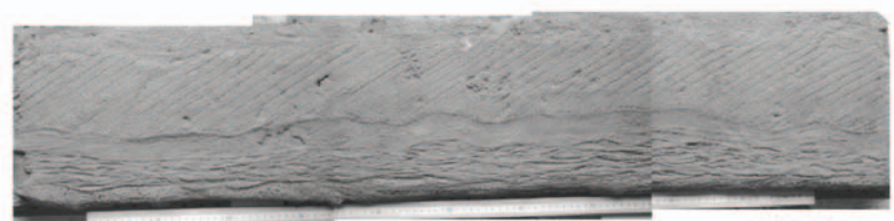

Panel 4

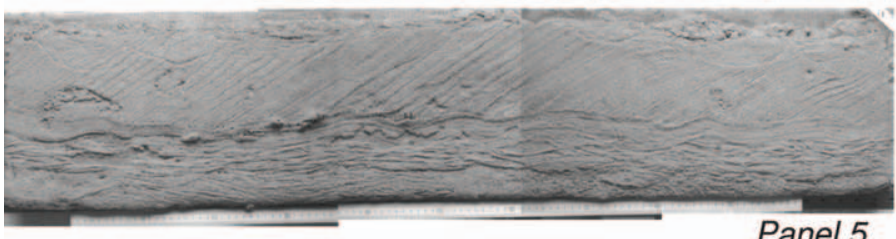

Panel 5

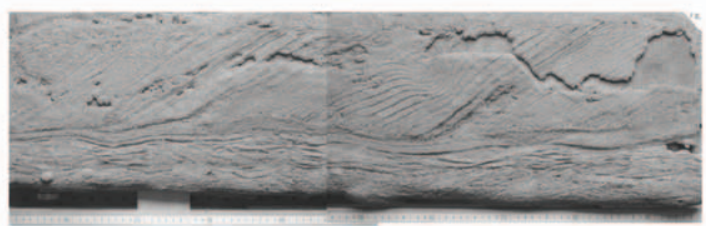

Panel 6

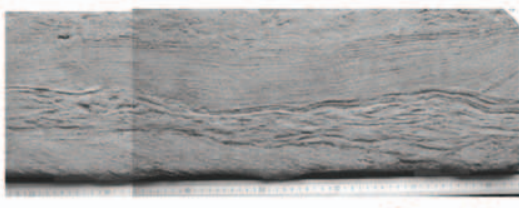

Panel 7

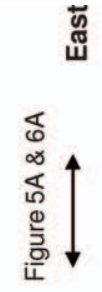

焉

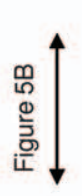

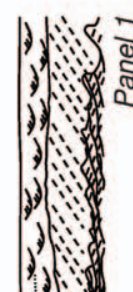

3)

(2) (1).

(y)

(3)

3)

○ิ

19.

$(4)$

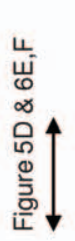

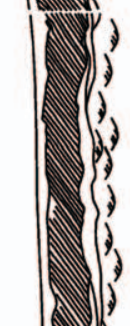

3

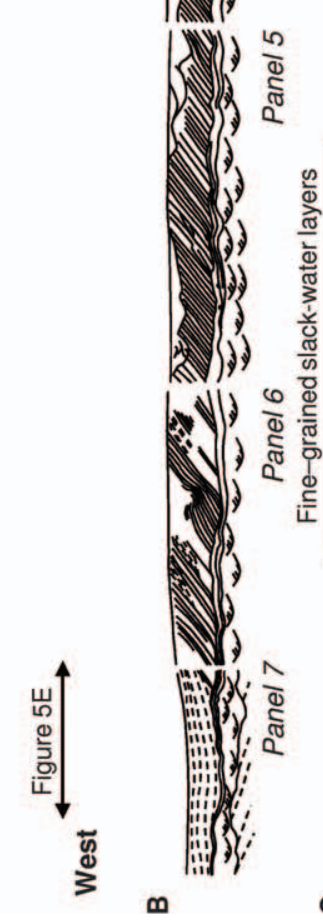

एक

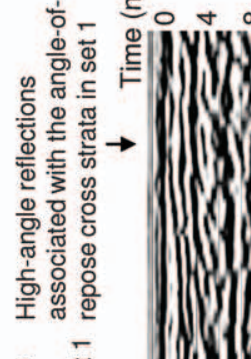

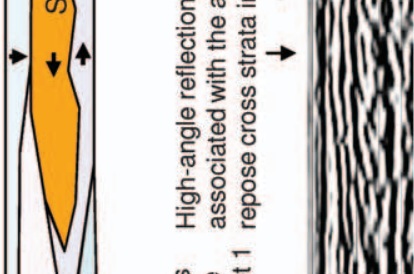

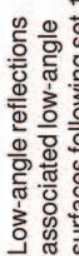

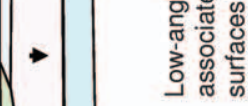

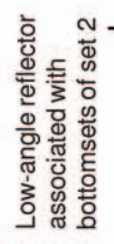

$+$

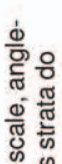

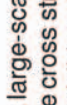

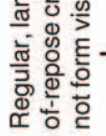

$\downarrow$

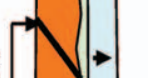

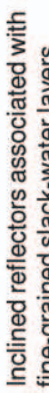

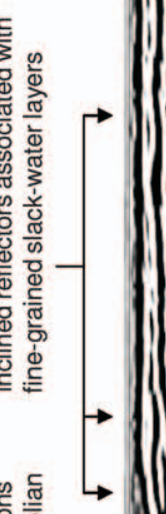

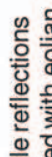

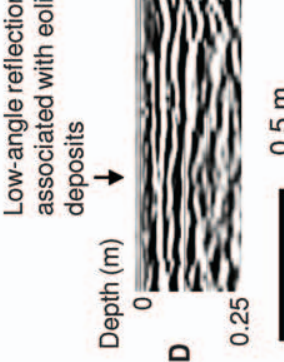

Journal of Sedimentary Research sedp-81-11-06.3d 15/9/11 14:36:13 
Large-scale set of thick angle-of-repose cross strata

Large-scale set of thin angle-of-repose cross strata

Small-scale sets of thin (trough) cross strata

Climbing small-scale sets of thin (trough) cross strata

$\square$ Small-scale sets of thin trough cross strata on an inclined surface

Planar and low-angle drapes of sand and silt, interfingering with foresets

$\square \quad$ Planar and low-angle drapes of sand

$\rightarrow \quad$ Flow direction (downward arrow indicates flow perpendicular to profile)

- Fine-grained, organic rich layers indicating a slack water stage

Small-scale (trough) cross strata

Climbing sets of small-scale cross strata

IIII Distinct sedimentary boundaries or fine-grained drapes

Eシシ彡二- Thin cross strata

FIG. 4.-Continued.

these thin cross strata implies that superimposed bedforms were insignificant relative to the sorting during deposition (e.g., thin bedload sheets).

\section{Thick Cross Strata in the Downstream Part of Set 2}

The cross strata in set 2 change into regularly spaced, angular, thick $(13.4( \pm 2.7) \mathrm{mm})$ cross strata that are delineated by fine-grained drapes (Figs. 5D, 6F). The thick cross strata have both thin internal layering (Fig. 6E) and a larger-scale internal coarsening-outward sorting pattern. The two superimposed sorting patterns are attributed to the internal sorting within the formative superimposed ripples and sorting during deposition by grainflows (Reesink and Bridge 2007, 2009). The internal lamination formed by grainflows rules out grainflows as the cause of the larger-scale coarsening-outward sorting pattern. The thicker sorting pattern of the strata is thus associated with the internal sorting of superimposed bedforms (Fig. 7). The regularity of the cross strata is the product of the regularity of the formative superimposed bedforms and as such clearly distinguish the cross strata from sorting patterns developed by flow unsteadiness. The visibility of internal layering by grainflows decreases when the pre-sorting by the superimposed bedform increases. The average height of the downstream part of set 2 is $0.14 \mathrm{~m}$. The crosssectional area of the thick cross strata $\left(3750( \pm 760) \mathrm{mm}^{2}\right)$ was larger on average compared to those of ripples measured near the location (1600 $\left.( \pm 800) \mathrm{mm}^{2}\right)$, but does not exceed realistic values for ripple sizes (e.g., heights of $38 \mathrm{~mm}$ and lengths of $0.2 \mathrm{~m}$ are not uncommon). The thick cross strata make up most of the unit-bar deposit (Fig. 4). The change in stratal sorting in set 2 from thin cross strata (grainflows) without evidence of pre-sorting to thick cross strata attributed to superimposed ripples is explained as a change from bedload sheets to well-developed ripples.

\section{Along-Stream Changes in the Grain-Size Sorting of Thick Cross Strata in Set 2}

The variable visibility of the fine-grained drapes and internal sorting patterns is associated with temporal changes in the superimposed bedform shape and grain-size segregation within them (e.g., change from ripples to bedload sheets, differences in ripple character). The changes in the internal grain-size segregation, hence change in characteristics of the superimposed bedforms, are thus attributed to changes in flow and sediment transport conditions on the back of the unit bar. Decreased visibility of the fine-grained drapes in the downstream direction are observed in several places along the profile and terminate with a drape of fine-grained and organic material that is associated with stagnant water and low-flow stages (Fig. 4, panels 5, 6). The decreases in the visibility of the fine-grained drapes are thus associated with the change from ripples to poorly developed ripples or bedload sheets during a waning flow stage. The repetition of this pattern along the set indicates that the unit bar persisted through a number of floods.

\section{Lateral Extent of Cross Strata Formed by Superimposed Ripples in Set 2}

The thick cross strata in set 2 are laterally continuous (Fig. 3). Lateral terminations of the thick cross strata are associated with lateral terminations of the superimposed bedforms. Such terminations are typically identified based on lateral fading out of the fine-grained drapes that delineate the cross strata. In this case, the fine-grained drapes (related to superimposed bedform troughs) are far more distinctive than the internal sorting of the cross strata (related to superimposed bedforms). The lateral continuity of the thick cross strata is therefore associated with ripples with well-developed and laterally continuous troughs. The lateral continuity of the fine-grained drapes does not provide any additional information on the sinuosity of the ripples because the shape of the strata is dictated by the shape of the bar slope. Measurements of the lateral continuity of exposed ripples indicate that sinuous-crested ripples extend $0.7( \pm 0.6) \mathrm{m}$ on average, with lengths measured up to $4 \mathrm{~m}$. These measurements are made on exposed ripples, which have been modified and dissected by the receding flow before being exposed. The measurements of the exposed ripples are therefore likely to underestimate the real lateral extent of the ripples.

$\leftarrow$

FIG. 4.-A) Epoxy peels of the trench at location 1, their interpretation: B) detailed structures and C) depositional units with direction of aggradation (arrows), and D) concurrent GPR image. Main river flow direction is out of the profile; the dominant local direction of aggradation is along the profile to the left. 
A

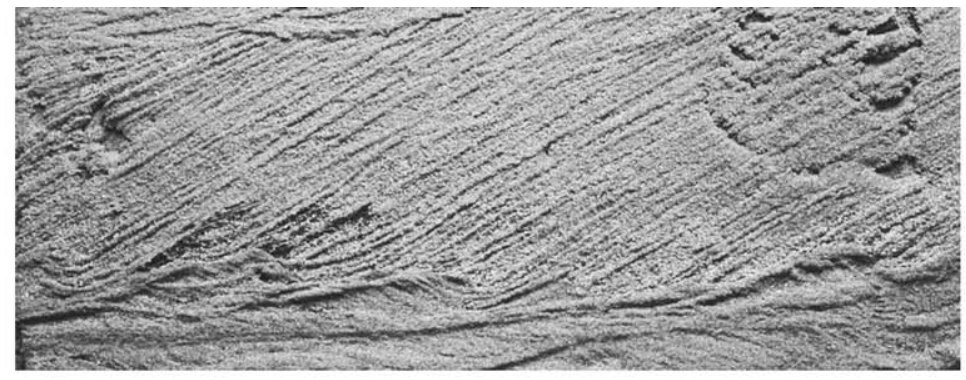

B

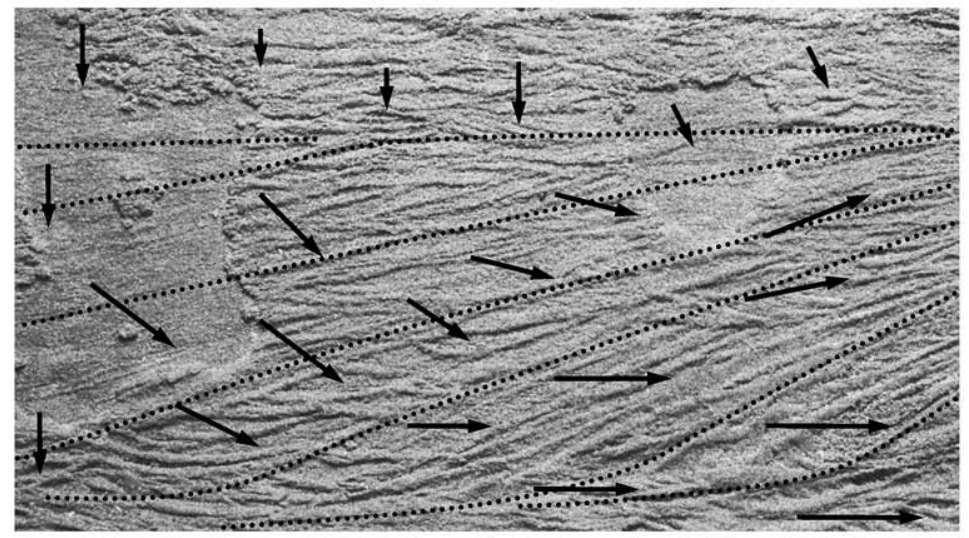

C

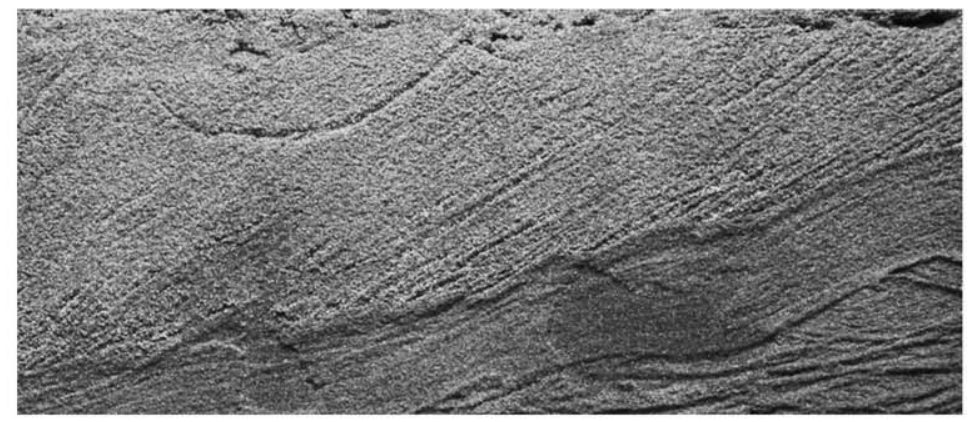

D

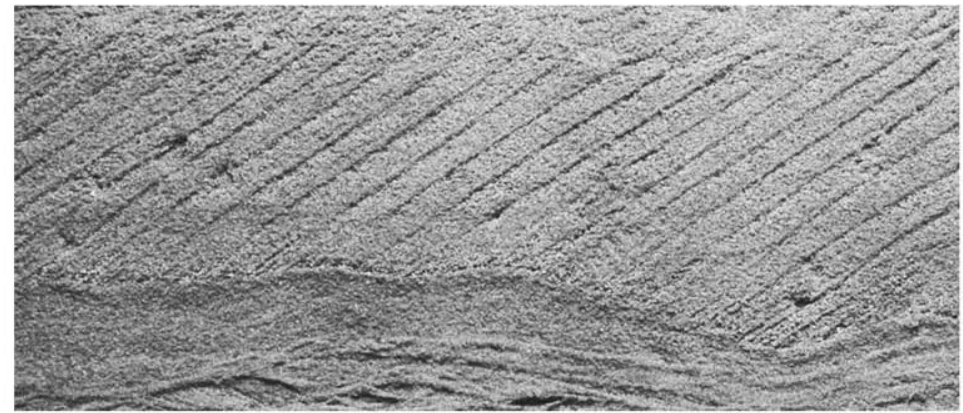

E

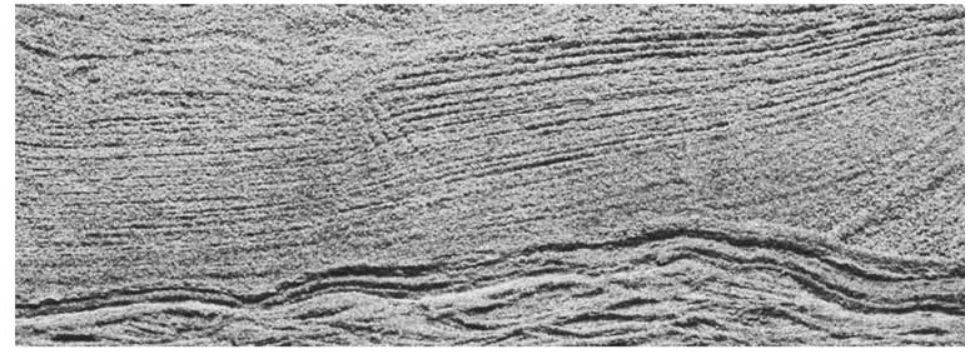

$0.10 \mathrm{~m}$
FIG. 5.-Details of the epoxy peels of location 1: A) Thin cross strata delineated by fine-grained drapes and with internal small-scale cross strata from the upstream part of set $1 ; \mathbf{B}$ ) low-angle surfaces with small-scale sets, arrows point into the direction of migration: down $=$ out of profile, horizontal $=$ along the profile, and diagonal $=$ oblique; note that some return-flow ripples climb onto the bar foresets; $\mathbf{C}$ ) cross strata associated with grainflows and a lack of significant presorting by superimposed bedforms (upstream part set 2), underlain by low-angle grainfall deposits that interfinger with the set; $\mathbf{D}$ ) cross strata associated with superimposed ripples and delineated by fine-grained drapes (downstream part set 2; note that these thick cross strata have internal layering associated with grainflows, which are best visible at the base of the cross strata); E) eolian strata. 

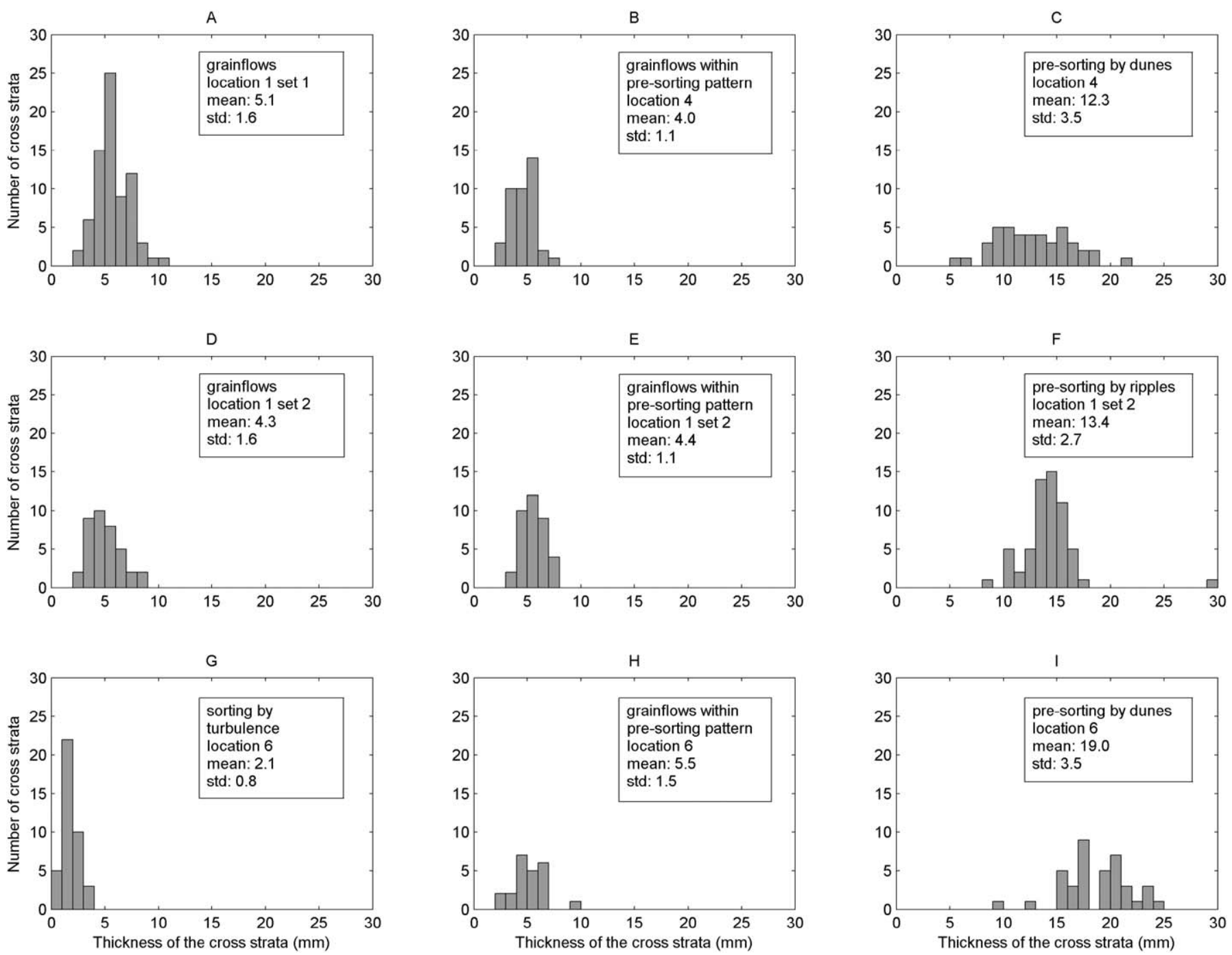

FIG. 6.-Histograms of thicknesses of cross strata: A) attributed to grainflows and separated by fine-grained drapes, set 1 location 1, B) attributed to grainflows within a larger-scale sorting pattern, location 4, C) sorting pattern attributed to superimposed dunes, location 4, D) attributed to grainflows with no other visible sorting pattern, set 2 location 1, E) attributed to grainflows within a larger-scale sorting pattern, set 2 location 1, F) sorting pattern attributed to superimposed ripples, set 2 location 1, G) tangential strata attributed to turbulence, location $6, \mathbf{H}$ ) attributed to grainflows within a larger-scale sorting pattern, location 6 , I) sorting pattern attributed to superimposed dunes, location 6.

\section{Ground-Penetrating Radar (GPR)}

The visibility of GPR reflections from sedimentary structures depends on the size and contrast in electrical properties of the structures and the nature of the overlying sediment. The reflections observed in the $900 \mathrm{MHz}$ GPR survey represents the detailed sedimentary structures poorly (Fig. 4). In particular, the thick angle-of-repose cross strata are not represented by high-angle inclined reflectors. Instead, the GPR image of the large-scale sets is dominated by horizontal reflections. The dominance of horizontal reflections is attributed to the reverberations of the air and ground waves. The thick cross strata apparently have insufficient thickness and contrast in electric properties to form individual reflections. Distinct reflections were found in association with the low-angle surfaces composed of small-scale trough cross strata and drapes of fine-grained and organic material associated with slack-water stages. The bottomsets of the large-scale sets did form consistent reflectors, which is attributed to the distinct difference in grain size between the bottomsets and the angleof-repose cross strata. Such changes in grain size are associated with distinct changes in porosity and the percentage of fines (including clay), which cause sufficient change in the electrical properties to cause reflections.

\section{UNIT BARS WITH SUPERIMPOSED DUNES}

\section{Location 2}

Location 2 (Figs. 1, 3, 8) was chosen because dunes with superimposed current ripples were exposed on top of the unit bar. The unit bar was located at the head of a compound braid bar (Fig. 3) and migrated in a downstream direction relative to the main flow. The surface of the unit bar was located close to the daily water level, and the unit bar was fully or partially submerged during the night-time high flows during the investigation. The unit-bar lee slope was approximately $0.2 \mathrm{~m}$ high and had a reduced slope of approximately 10 degrees as a result of swash and backwash of waves on the unit-bar lee slope (Fig. 8). The formation of the beach surfaces on the unit-bar lee slope was observed daily during the low-flow stage. Migration of the unit bar occurred during high-flow stage at night. Both current ripples and wave ripples were observed in the area, 


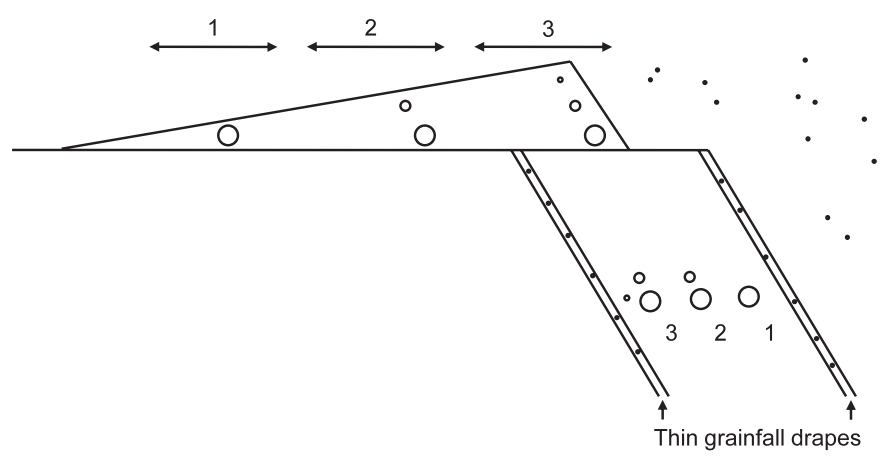

FIG. 7.-Conceptual model of the relation between pre-sorting within superimposed bedforms and the sorting within associated cross strata. The numbers indicate how the along-stream sorting of the superimposed bedforms (hence timing and order of consecutive deposition) relates to the sorting within the

and it is assumed that many ripples are in fact formed by a combination of waves and river currents. The exposed dunes were $0.12( \pm 0.025) \mathrm{m}$ high and $2.2( \pm 0.4) \mathrm{m}$ long. The heights of the superimposed dunes is larger than $25 \%$ of the unit-bar height $(H s / H \approx 0.6)$ and the arrival of dunes at the unit-bar brink point caused reduction of the unit-bar lee slope. Current ripples superimposed on the dunes and unit bar were approximately $17( \pm 6) \mathrm{mm}$ high and $130( \pm 23) \mathrm{mm}$ long, which is approximately $14 \%$ of the height of exposed dunes and $9 \%$ of the height of the unit-bar. In view of their limited height, the ripples were not capable of reducing the lee slopes of the host dunes or host unit bar.

\section{Internal Structures}

The core of the unit bar at location 2 was composed of inclined medium-scale sets that developed in the downstream direction into a large-scale set with the height of the unit-bar front. In places, the medium- and large-scale sets are interrupted by low-angle planar strata with interbedded wave ripples (De Raaf et al. 1977). The topsets of the unit bars are composed primarily of dune sets and include a limited number of ripple sets. The core of the bar thins in the upstream direction (southeast, left in Fig. 8). The last three nightly floods (before the epoxy peels were made) formed increments of migration that are separated by distinct beach deposits of which the formation was observed during the day. The first of the nightly floods had a higher peak-flow stage than the last one, which is reflected in the larger cross-sectional area of the sediment between the beach deposits (Fig. 8). The medium-scale cross strata are mostly tangential in profile whereas the large-scale cross strata (height of the unit-bar slope) are mostly angular in profile. In a few locations, a transition is observed from medium-scale tangential strata to large-scale angular strata within the same cross-stratified set. In these cases, the distinction between medium- and large-scale strata is gradual and the interpretation is subjective. Thick cross strata attributed to presorting by superimposed ripples are found in places in the medium- and large-scale sets and indicate that (current) ripples were superimposed dunes and bar (Fig. 9). These thick cross strata are identified by the presence of fine-grained drapes, partial reactivation surfaces at the top of the set, and their distinction from thinner internal lamination that is attributed to grainflows (4-5 mm thick). The bar core of medium- and large-scale sets is underlain primarily by small-scale sets of millimeter- thick cross strata $(\sim 2 \mathrm{~mm}$ ) but also by a number of thin sets with slightly thicker cross strata $(\sim 5 \mathrm{~mm})$. The bimodal thickness distribution of the underlying sets suggests an origin from both ripples and dunes (Fig. 10A). The underlying deposit also includes laterally discontinuous horizontal or low-angle strata that are interpreted as beach deposits formed in unit-bar troughs, some localized areas where bubble sand obscures the stratification and post-depositional deformation structures.

\section{Interpretation \\ Down-Climbing Sets}

The medium-scale sets in the bar core and topsets are formed by dunes migrating over the back of the unit bar. Superimposed dunes migrate faster than the host unit bar and overtake it. The unit-bar lee slope is reestablished once the dune overtakes the unit-bar slope. The downstream end of the sets formed by this process are lower (here $\sim 0.1 \mathrm{~m}$ ) than the upstream parts of the sets and can therefore be referred to as downclimbing sets (cf. Allen 1982). The set changes from a medium-scale set formed by a dune on a bar to large-scale set formed by migration of the bar slope (Fig. 9B). The distinction between medium-scale and large-scale is therefore inherently ambiguous in this case. The simultaneous change within this set from tangential strata in the medium-scale part to angular cross strata in the large-scale part is attributed to a decrease in turbulence affecting the slope with increasing slope height (Reesink and Bridge 2009). The thick cross strata formed by ripples that are superimposed on the dune while the dune migrates down the bar slope can be used here to improve the interpretation. If it is assumed that the superimposed ripples are of a constant size and cross-sectional area-which is reasonable in view of the fairly uniform geometries of ripples in the area-then the thickness of ripple-formed cross strata can be used to interpret the size of host dunes and unit bars. Firstly, the thicknesses of the cross strata that are associated with superimposed ripples change little in downstream direction (Fig. 9A). This suggests that the down-climbing dunes did not vary much in height: the height of the host and volume of the ripples control the thickness of the cross strata. Secondly, the cross-sectional area of the cross-strata increases threefold from the medium-scale part to the large-scale part of the set where the stratal cross-sectional volumes approximate the cross-sectional volumes of realistic ripples (Fig. 9C). The increase in cross-sectional area of the cross strata implies that the set thickness represents a larger proportion of the original bedform height. Thirdly, the cross-sectional volume and set thickness increase threefold from the medium-scale set to the large-scale set. The bar height has indeed remained nearly identical during the investigation of the bar. The stratal volume in the medium-scale part of the set suggests that approximately a third of the formative superimposed dune remained preserved here. This observation supports the notion that approximately a third of a dune set is preserved in uniform flows such as on the tops of bars (Leclair and Bridge 2001). However, the deceleration of the flow over the bar lee slope causes locally increased aggradation and deceleration of the superimposed bedforms, which results in significant increase in preservation. This observation is in agreement with the ruling model of bedform preservation (Leclair and Bridge 2001), which was not developed or tested for non-uniform flow conditions and down-slope migration of bedforms.

\section{Bottomsets and Trough Deposits}

Beside the fine-grained ripple sets that are characteristic as the bottomsets of unit bars, the trough deposits of this unit bar also include

Fig. 8.-A) Epoxy peels of the trench at location 2, their interpretation: B) detailed structures and C) depositional units, and D) concurrent GPR image. Main river flow direction and dominant direction of aggradation are along the profile to the right. 
A

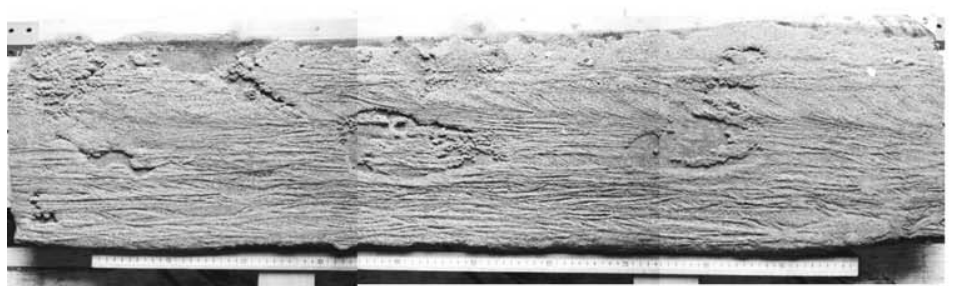

Panel 1

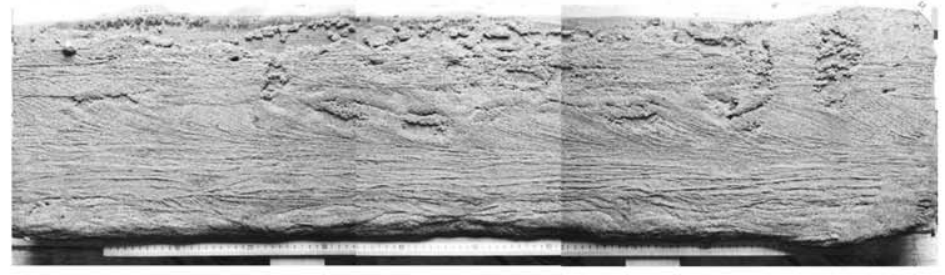

Panel 2

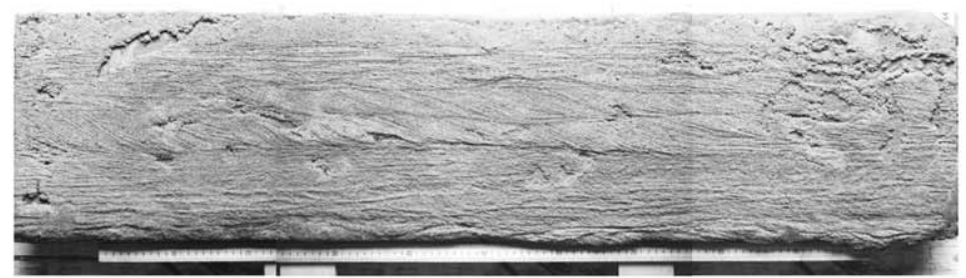

Panel 3

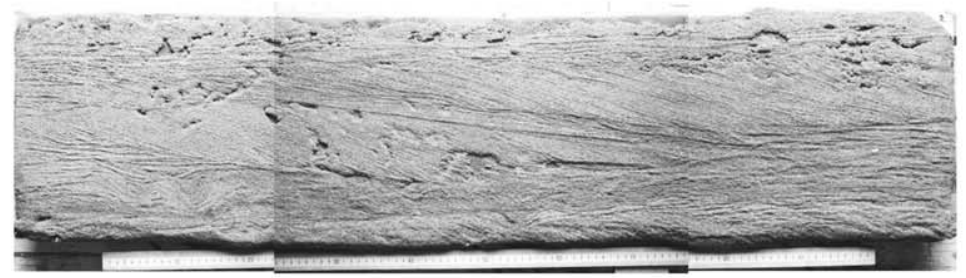

Panel 4

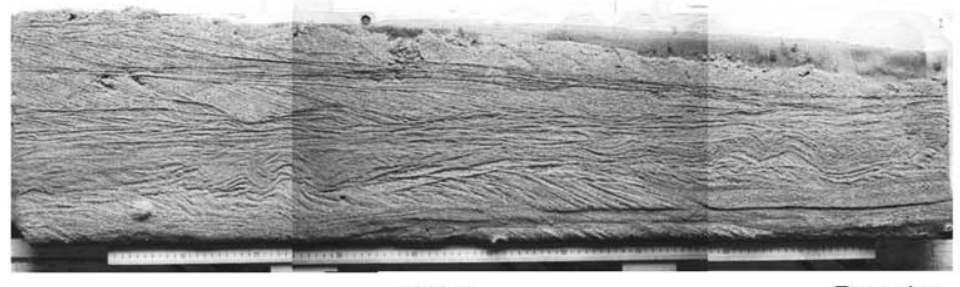

$0.5 \mathrm{~m}$

Panel 5

$\square$ Primarily large-scale set of thick angle-of-repose cross strata

$\square$ Small- and medium-scale sets of thin (trough) cross strata

Planar and low-angle drapes of sand

$\rightarrow \quad$ Flow direction

Small-scale (trough) cross strata

Distinct sedimentary boundaries or fine-grained drapes

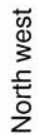

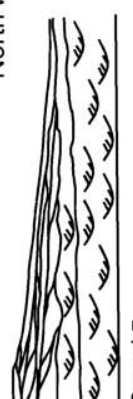

तั

$\frac{1}{0}$
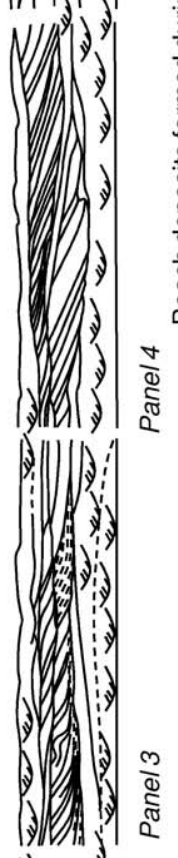

(3)

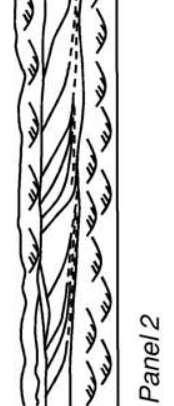

난

(1)

is

(2)

(i)

(a)

(3)

莺

(.) $(y)$ एक

m

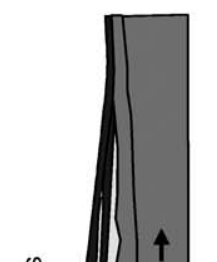

1

$\stackrel{\Phi}{\varepsilon} \uparrow$

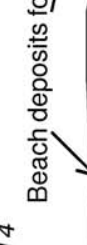
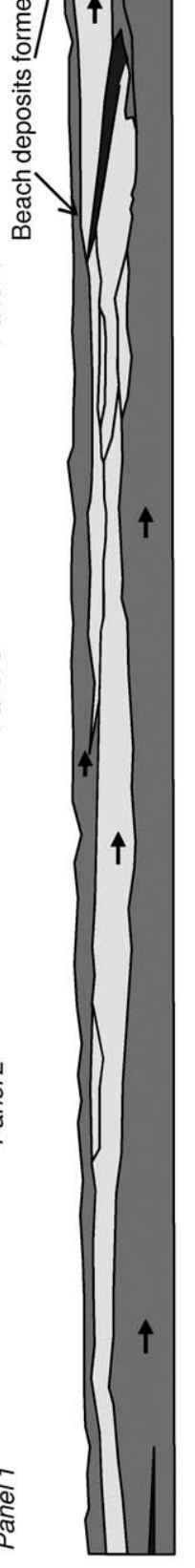

0
(5)

$\stackrel{\text { है }}{\stackrel{0}{\xi}}$

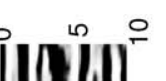

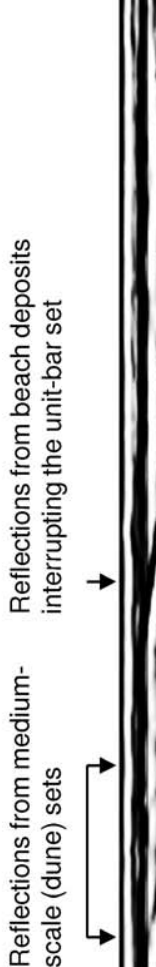

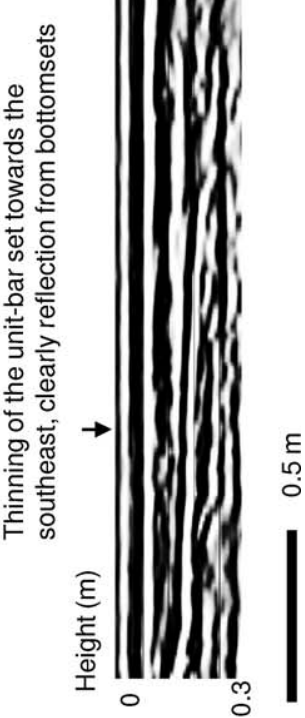

口 
A

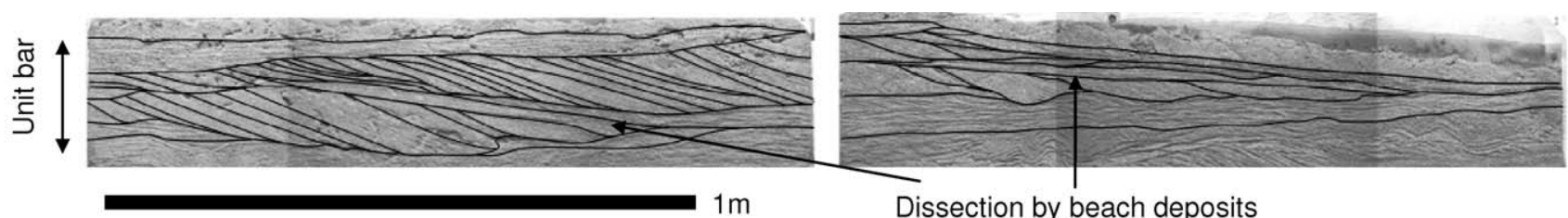

$1 \mathrm{~m}$

Dissection by beach deposits

B

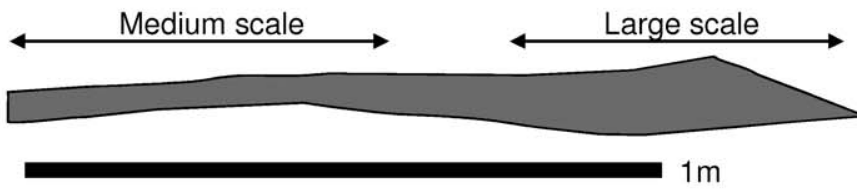

Cross strata inconsistent - not included in analysis

C

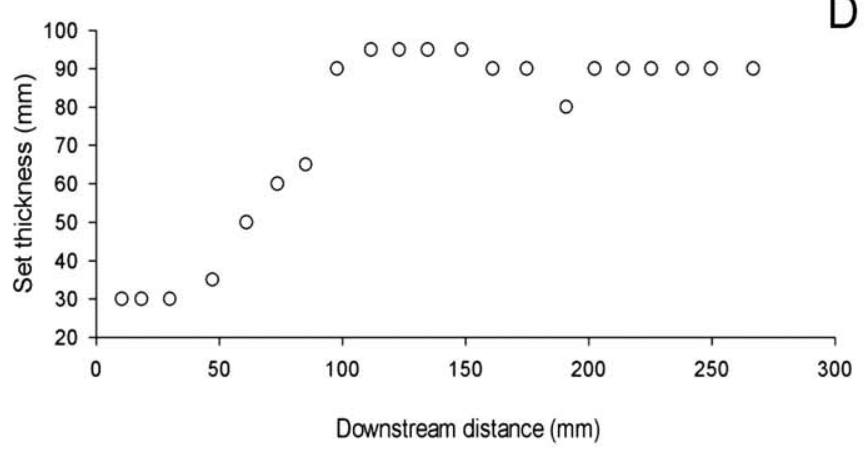

D

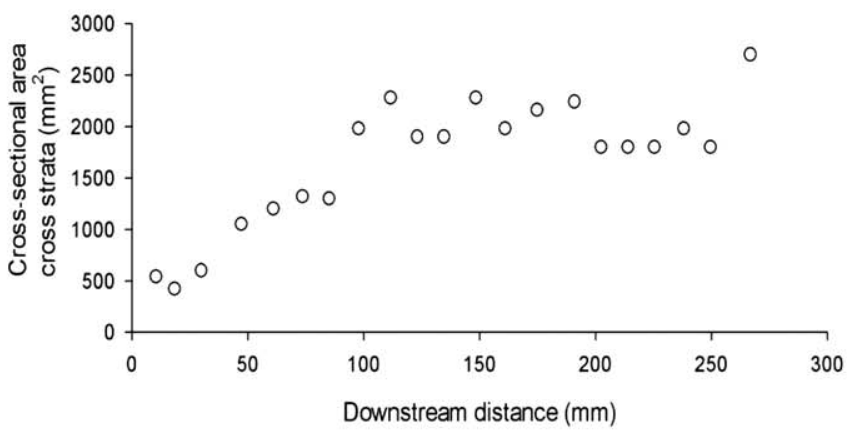

FIG. 9.-Details from location 2: A) interpreted epoxy peels of dune sets migrating down a unit bar slope with cross strata attributed to superimposed ripples and local beach deposits. B) The upper inclined dune set shows C) a distinct simultaneous increase in set thickness and D) cross-sectional area of the cross strata. Assuming that the superimposed ripples had relatively constant cross-sectional areas, the observed downstream increase in preserved cross-sectional area indicates that an increased proportion of the original set is preserved.

wave ripples and beach deposits formed in unit-bar troughs. The presence of bubble sand in the bar trough structures indicates that the unit-bar trough must at times have been fully emergent and hence provides a useful indication of the high elevation of the trough deposits relative to mean water levels. Clearly, the depositional processes in bar troughs are diverse and the transition from the influence of the separated flow to the channel floor is gradual and temporally variable.

\section{Set Thicknesses}

The bimodal thickness distribution of sets in the trough deposits implies that set thicknesses of ripples and dunes overlap (Fig. 10A). The gradual transition from a medium-scale dune set to a large-scale unit-bar set implies that the distinction between dunes and bars is equally ambiguous in specific cases. Clearly, set thickness on its own is not an infallible criterion for the genetic interpretation of sets. Cross-stratal sorting patterns can be used to relieve some of this ambiguity. For example, the bar- and dune-formed parts of a single set were distinguishable here by the relative volume of the thick cross strata associated with superimposed ripples (Fig. 9). Similarly, the difference between cross strata of dunes and ripples is normally readily observed. Grainflows do not fully develop or involve much sediment on ripple-scale slopes and are consequently expected to be thinner. Such sedimentary dynamics can be used to add process-based criteria to any genetic interpretation of sets.

\section{Ground-Penetrating Radar}

The structures that could be identified in the $900 \mathrm{MHz}$ GPR image were limited to the low-angle planar strata of the beach deposits that interrupt the medium- and large-scale sets in the unit-bar deposit. In places, reflections from the bottomsets of medium-scale sets could be identified. The bottomsets of the unit bar (large-scale set) formed a strong and continuous reflector and showed the thinning of the unit-bar set towards southeast (left of profile, Fig. 8).

\section{Location 3}

Location 3 was chosen because exposed dunes with superimposed ripples were observed on the unit bar days before the investigation. Location 3 is located near the main channel (Figs. 1, 11) of the river and was flooded every night during the field investigations only to be exposed during lower water levels in the afternoon. The unit-bar lee slope varied laterally in height between 0.15 and $0.3 \mathrm{~m}$. Three stakes were placed at the unit-bar front before the investigation to track the migration of the unit bar. The stakes indicated that the unit bar migrated 1.5 and $2 \mathrm{~m}$ over two subsequent nights. After those events, the unit bar was still inundated every night but did not migrate any significant distance $(<5 \mathrm{~cm})$. Dunes of approximately $0.1 \mathrm{~m}$ high and $1 \mathrm{~m}$ long were present on the back of the unit bar during these first two high-water events. High-water marks (floating algae on wooden stakes) indicated that water depths during this first flood were on the order of $0.2-0.4 \mathrm{~m}$. The dunes superimposed on the unit bar were replaced by current ripples during later floods with water depths in the order of $0.05-0.1 \mathrm{~m}$. The ripples superimposed on the dunes were $19( \pm 0.6) \mathrm{mm}$ high and $160( \pm 40) \mathrm{mm}$ long. In view of their relative heights $(H s / H=0.33-0.67)$, passage of dunes is expected to form lowangle reactivation surfaces. Superimposition of ripples is not expected to cause reduction of the lee slope of the dunes $(\mathrm{Hs} / \mathrm{H} \sim 0.19)$, nor the unit $\operatorname{bar}(H s / H=0.06-0.13)$. 

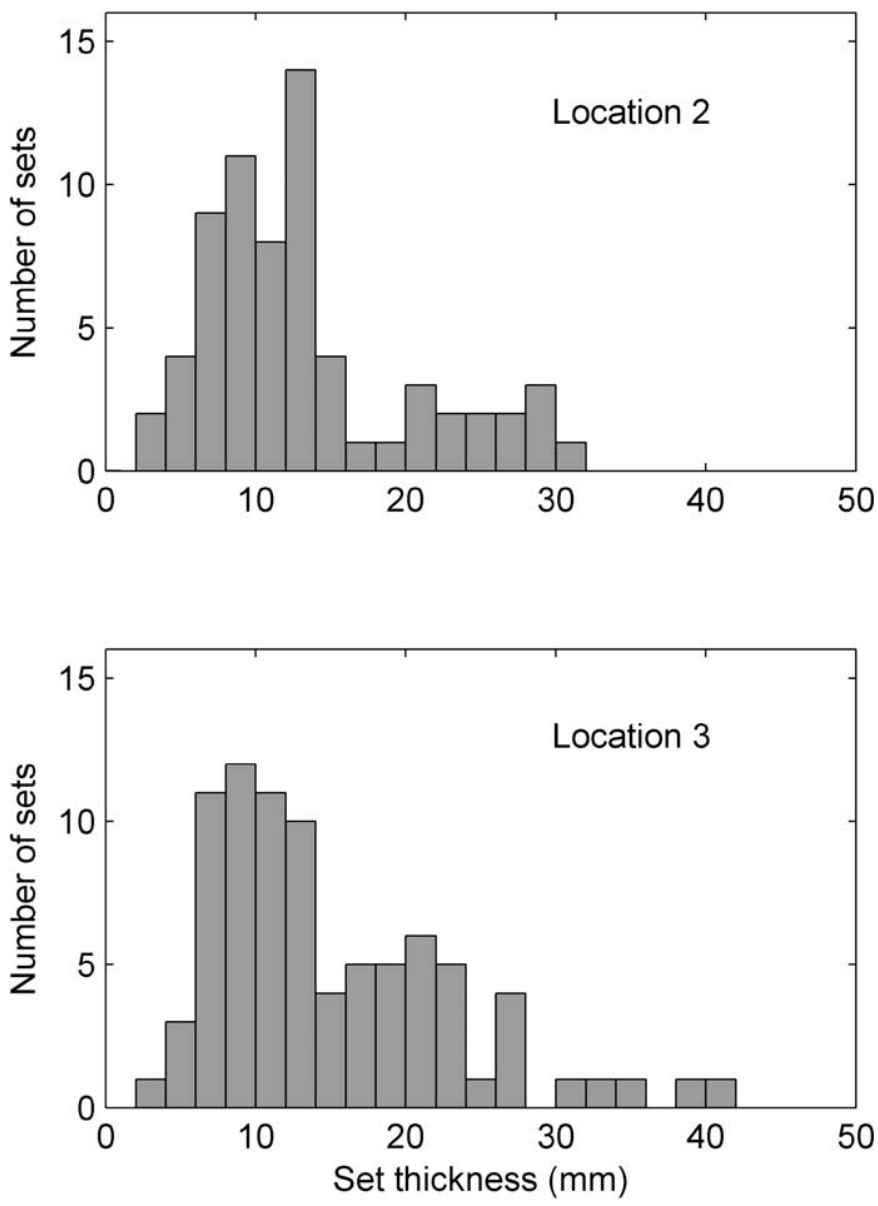

FIG. 10.-Histogram of the vertical thicknesses of sets in the deposits underlying the large-scale sets of $\mathbf{A}$ ) location 2 and $\mathbf{B}$ ) location 3. The bimodal distributions indicate origins from both ripples and dunes.

\section{Internal Structures}

The large-scale set that makes up the foresets of the unit-bar deposit is underlain and overlain by medium- and small-scale sets (Figs.12, 13). The bimodal distribution of the set thicknesses in these layers indicates an origin from both ripples and dunes (Fig. 10B). At the very bottom of the profile, the top of another large-scale set of thick cross strata is visible. The compound bar is thus composed of stacked unit bars. The origin of the reactivation surfaces in the profile is known because the migration of the lee slope was observed and measured. Reactivation surfaces associated with flow unsteadiness are associated with a wedge of thick bottomsets. This thick base was not found in reactivation surfaces that are associated with superimposed dunes (Figs. 12, 13). The time involved in the migration of the dunes and the formation of the reactivation surfaces was in the order of one to two hours. This is known because four to six dunes migrated over the brink point over a period of less than 12 hours (one flood). The cross-sectional area in between reactivation surfaces formed by dunes was approximately $0.3 \mathrm{~m}^{2}$. This cross-sectional area matches the cross-sectional area of dunes of approximately $1 \mathrm{~m}$ long and $0.06 \mathrm{~m}$ high, and these dimensions match the dimensions of exposed dunes found superimposed on unit bars in the area. Cross strata and partial reactivation surfaces associated with ripples superimposed on the dunes were observed only in places. The cross-sectional areas of unit-bar cross strata attributed to superimposed ripples were $2000( \pm 500) \mathrm{mm}^{2}$. The cross-sectional areas of ripples in the area are $1600( \pm 900) \mathrm{mm}^{2}$ on average. The large cross-sectional area of the preserved cross strata indicates that the cross strata are preserved almost entirely and that the foresets were not significantly reduced in height during their development.

\section{Interpretation}

Reactivation surfaces formed by flow unsteadiness are distinguishable from those formed by superimposed dunes $(H s / H=0.33-0.67)$ by the association with a wedge of sediment at the base of the reactivation surface. The buildup of a larger wedge of fine-grained material is attributed to the longer time involved in the reduction of a slope by a lowflow event. The presence of fine-grained wedges may thus provide

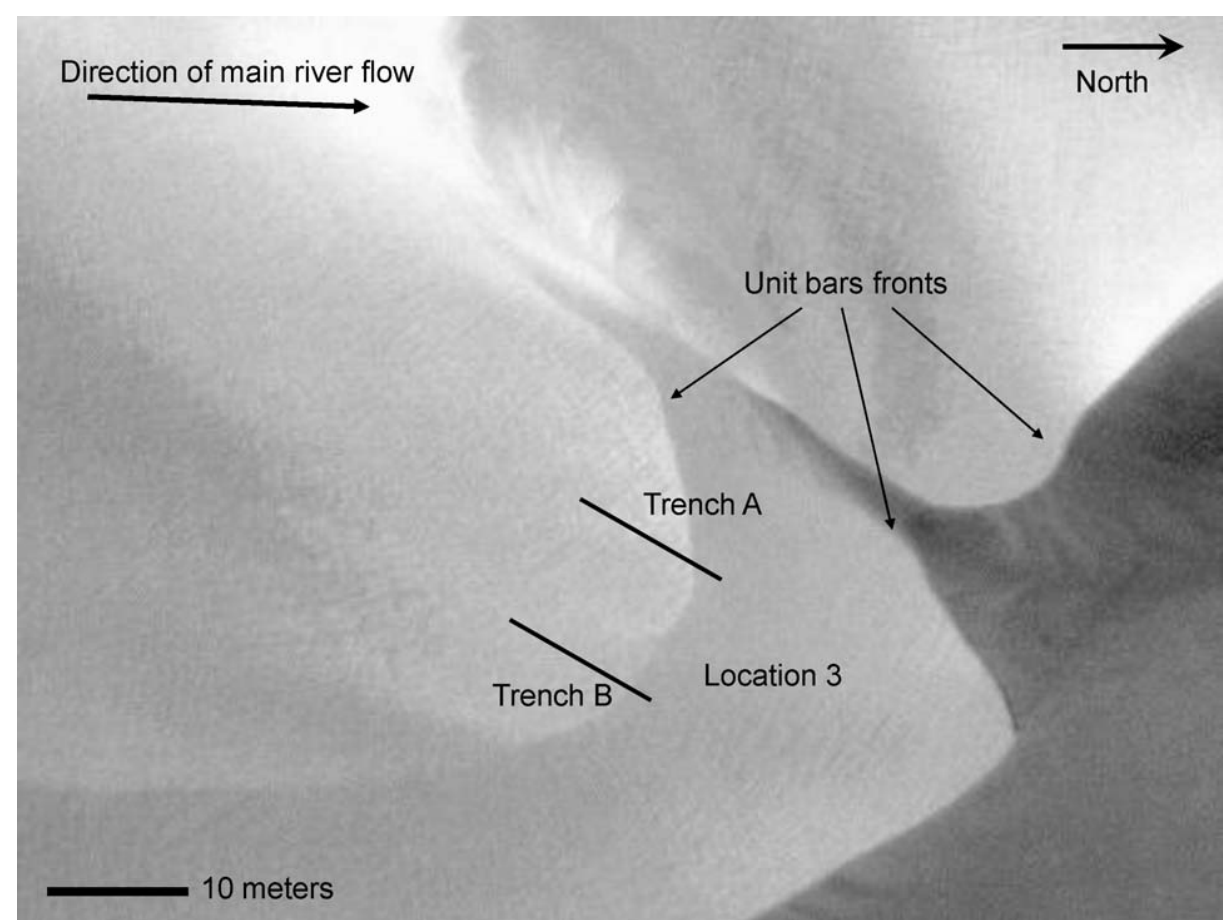

FIG. 11.-Aerial photograph of location 3. 
A
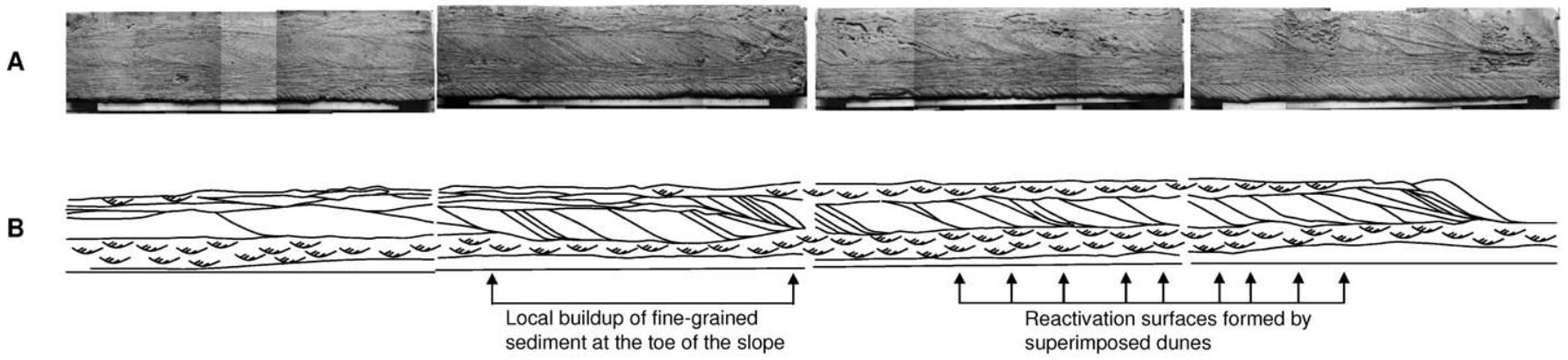

C
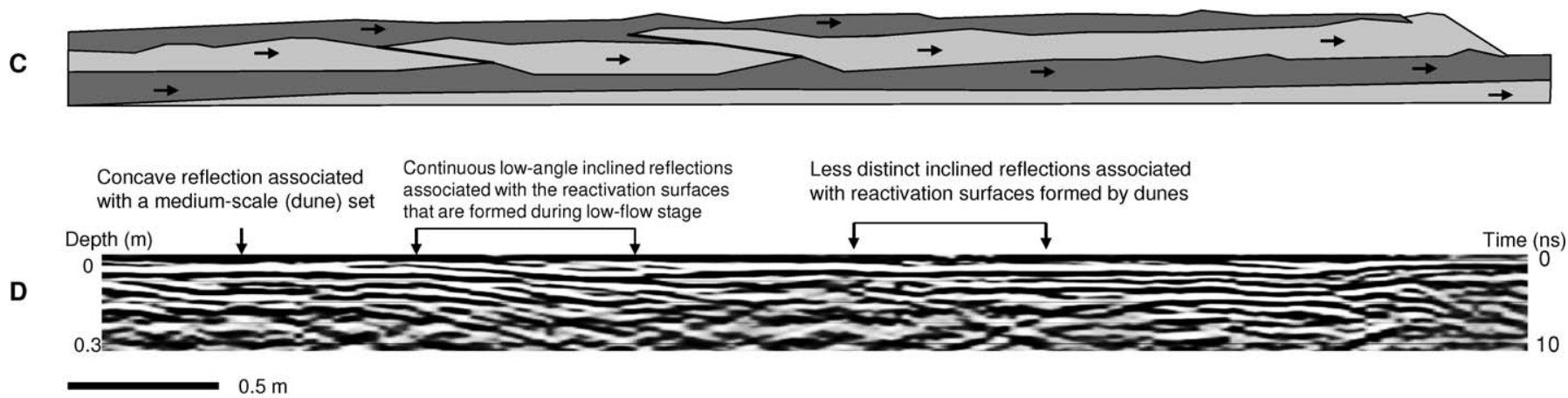

$\square \quad$ Primarily large-scale set of thick angle-of-repose cross strata

$\square$ Small- and medium-scale sets of thin (trough) cross strata

$\rightarrow \quad$ Flow direction

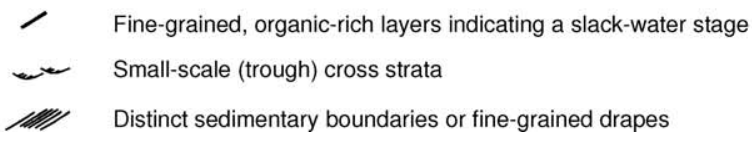

FIG. 12.-A) Epoxy peels of the trench at location 3A, $10 \mathrm{~m}$ from location 3B (Fig. 13). The interpretation of the epoxy peels: B) detailed structures and C) depositional units, and D) concurrent GPR image. Main river flow direction and dominant direction of aggradation are along the profile to the right.

evidence for the interpretation of the origin of an associated reactivation surface. However, a buildup of sediment is not guaranteed because sediment transport to the lee slope is not always significant. Indeed, the buildup of sediment varied between the two trenches (Figs. 12, 13). The cross-sectional area between reactivation surfaces formed by dunes compares to the cross-sectional area of the dunes (c.f. Rubin and Hunter 1982). The cross-sectional area between successive reactivation surfaces can therefore be used to constrain dune dimensions. Variability in the sorting patterns attributed to superimposed ripples indicates that the development of the superimposed ripples was not consistent. Where present, sorting patterns attributed to superimposed ripples imply that ripples were well developed on the back of the dunes, with both ripples and dunes migrating over the unit-bar lee slope. Such combinations of reactivation surfaces and cross-strata sorting narrows down the formative flow conditions considerably.

\section{Ground-Penetrating Radar}

The structures that could be identified in the $900 \mathrm{MHz}$ GPR image were limited to the reactivation surfaces in the large-scale set, the bottomsets of the large-scale set, and, in places, the bottomsets of medium-scale sets. In profile A (Fig. 12), the reactivation surface formed on 2 August is a clear, continuous reflector, whereas the base of the reactivation surface formed on 3 August is not clearly visible. In profile B (Fig. 13) the reactivation surfaces formed on 2 August is a discontinuous reflection, whereas the reactivation surface formed on 3 August is a clear continuous reflection. In places, reactivation surfaces formed by overtaking of the unit bar by dunes form inclined reflectors. Clearly, bottomsets and reactivation surfaces generate visible reflections. However, not every reactivation surface can be directly related to a distinct reflection.

\section{Location 4}

Location 4 was located in the Centre Angling River in the Cumberland Marshes area on an exposed mid-channel bar (Fig. 14). The unit-bar slope was well over 1 meter high and its base was not visible under the water. The top of the unit bar was covered by wind ripples in dry sand at the time of the investigation. The southern shallow and low-angle stoss slopes of the unit bars were covered with dunes $0.125( \pm 0.05) \mathrm{m}$ high and $9( \pm 1.2) \mathrm{m}$ long. Ripples in the same area were $0.039( \pm 0.013) \mathrm{m}$ high and $0.18( \pm 0.051) \mathrm{m}$ long. In view of their limited height $(H s / H<0.25)$, neither ripples $\left(H_{s} / H=0.02\right)$ nor dunes $\left(H_{s} / H=0.06\right)$ superimposed on the unit bar are expected to reduce the northern unit-bar lee slope. Ripples superimposed on dunes $(H s / H=0.3)$ could form reactivation surfaces within the dunes.

\section{Internal Structures}

Two epoxy peels were made to examine the sedimentary structures in detail (Fig. 14). The profile was oriented in a cross-stream direction and ended in the angle-of-repose slope at the side of the unit bar. The profile was composed of bottomsets, a large-scale cross strata set, and topsets with both small-scale sets formed by ripples and medium-scale sets formed by dunes. The base of the unit-bar set decreased in elevation in the 
South

A

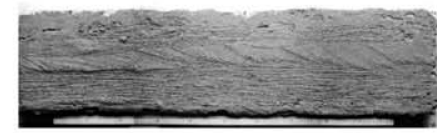

$\downarrow^{\text {August } 2^{\text {nd }}}$

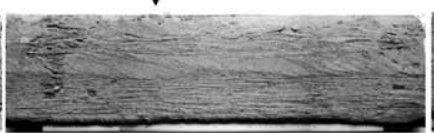

August $3^{\text {rd }}$

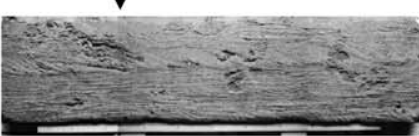

North

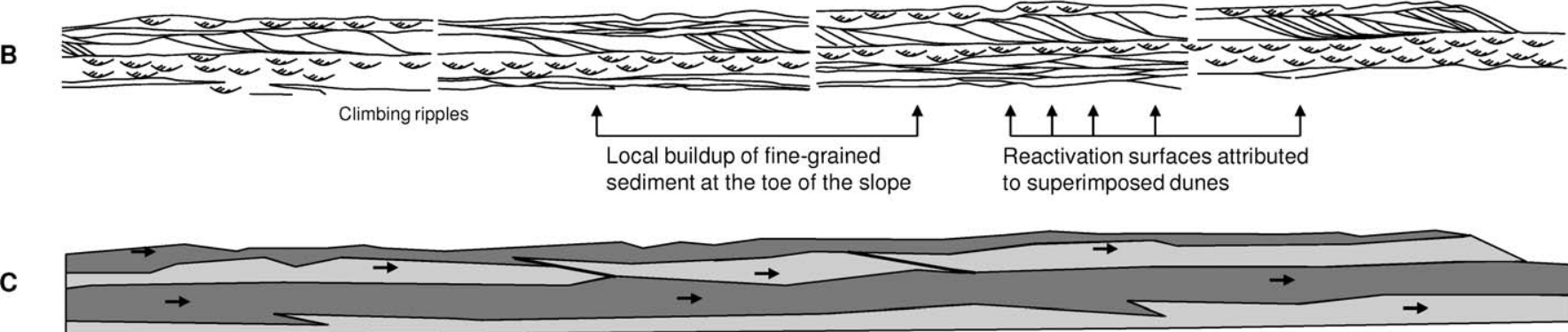

Continuous low-angle inclined reflections associated with the reactivation surfaces that are formed during low-flow stage

Less distinct inclined reflections associated with reactivation surfaces formed by dunes
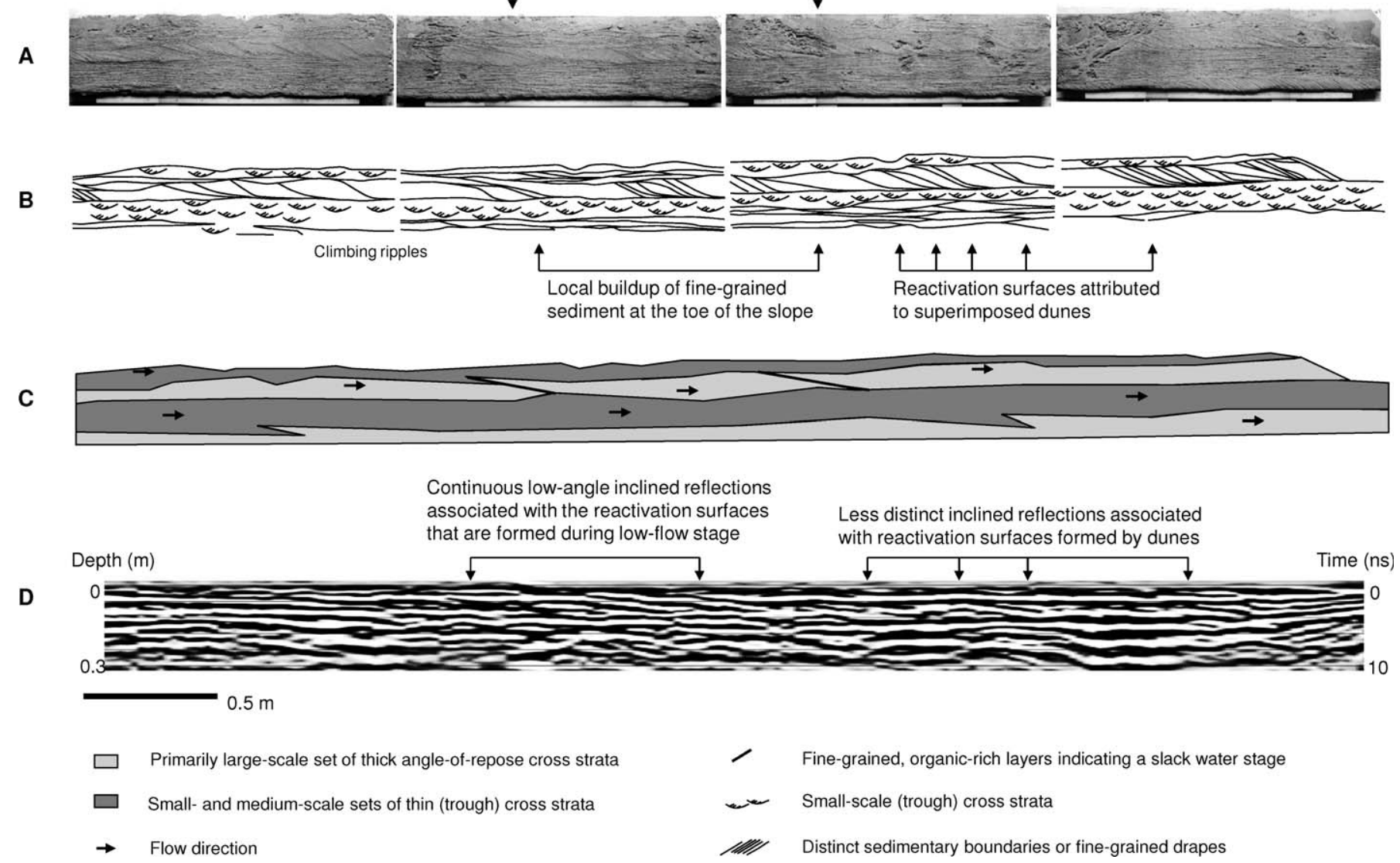

FIG. 13.-A) Epoxy peels of the trench at location 3B, $10 \mathrm{~m}$ from location 3A (Fig 12). The interpretation of the epoxy peels: B) detailed structures and C) depositional units, and D) concurrent GPR image. Main river flow direction and dominant direction of aggradation are along the profile to the right.

downstream direction. The epoxy peels and the trench face (Figs. 14) show that the large-scale set is composed of thick, large-scale cross strata that are interrupted by low-angle reactivation surfaces with wedges of small- and medium-scale sets at the top of the large-scale set. These sets that form and overlie the reactivation surfaces indicate directions of migration oblique and parallel to the unit-bar slope. The large-scale set is estimated to be over 1 meter thick at the location of the profile, based on field observations and the GPR survey. The large-scale cross strata show two superimposed sorting patterns: fine-grained drapes associated with superimposed dunes, and internal layering within the thick cross strata associated with grainflows. The sorting associated with the grainflows forms an internal stratification within the thicker cross strata that are associated with superimposed dunes. The average thickness of cross strata associated with superimposed bedforms were $12.3( \pm 3.5) \mathrm{mm}$, and those associated with grainflows were $4( \pm 1.1) \mathrm{mm}$ (Fig. 6B, C). The crosssectional area of the cross strata associated with superimposed bedforms is at least $0.25 \mathrm{~m}^{2}$, but it can be more considering that the base of the set was not observed. The cross-sectional area of the strata thus matches the cross-sectional area of the dunes found nearby, $0.32( \pm 0.16) \mathrm{m}^{2}$. The average cross-sectional areas of the ripples, $3500( \pm 1500) \mathrm{mm}^{2}$, is less than half of the sediment required for a grainflow on the 1+ meter-high unit-bar lee slope. Any sorting associated with ripples superimposed on the unit bar is therefore completely lost during the motion of the grainflows. Several medium-scale sets in the topsets of the unit bar with the same direction as the unit-bar set had reactivation surfaces within them that are attributed to ripples superimposed on host dunes. This confirms the observation that ripples in the area are large enough to reduce the slope of the dunes $\left(H_{s} / H=0.3\right)$. The preservation of the upper parts of the reactivation surfaces suggests that most of the dune set is preserved.

\section{Interpretation}

The medium- and small-scale trough sets that constitute the wedge of sediment in between the low-angle reactivation surface and the angle-ofrepose cross strata indicate a downstream (along-slope) direction of migration (cf. Collinson 1970). In contrast, the topset of the unit-bar deposit also includes sets that indicate an across-stream direction of migration. The across-stream flow is the result of refraction of the accelerated flow over the back of the unit bar. The accretion of this unit bar is thus characterized by changes in the direction of migration of the superimposed bedforms from across-stream (angle-of-repose cross strata formed by dunes) to along-slope (reactivation surfaces with trough cross strata). These variations are interpreted as the result of variations in flow stage, and flow direction at the crest of the unit bar.

\section{Ground-Penetrating Radar (GPR)}

The GPR image associated with the trench and the epoxy peels shows the distinct low-angle reactivation surfaces and a few large-scale cross strata in the far left of the image. Only few angle-of-repose cross strata are represented by inclined reflectors. Instead, horizontal reflectors (groundwater table, reverberations of the ground wave and air wave) and even inclined reflections that dip in the upstream direction are observed in 

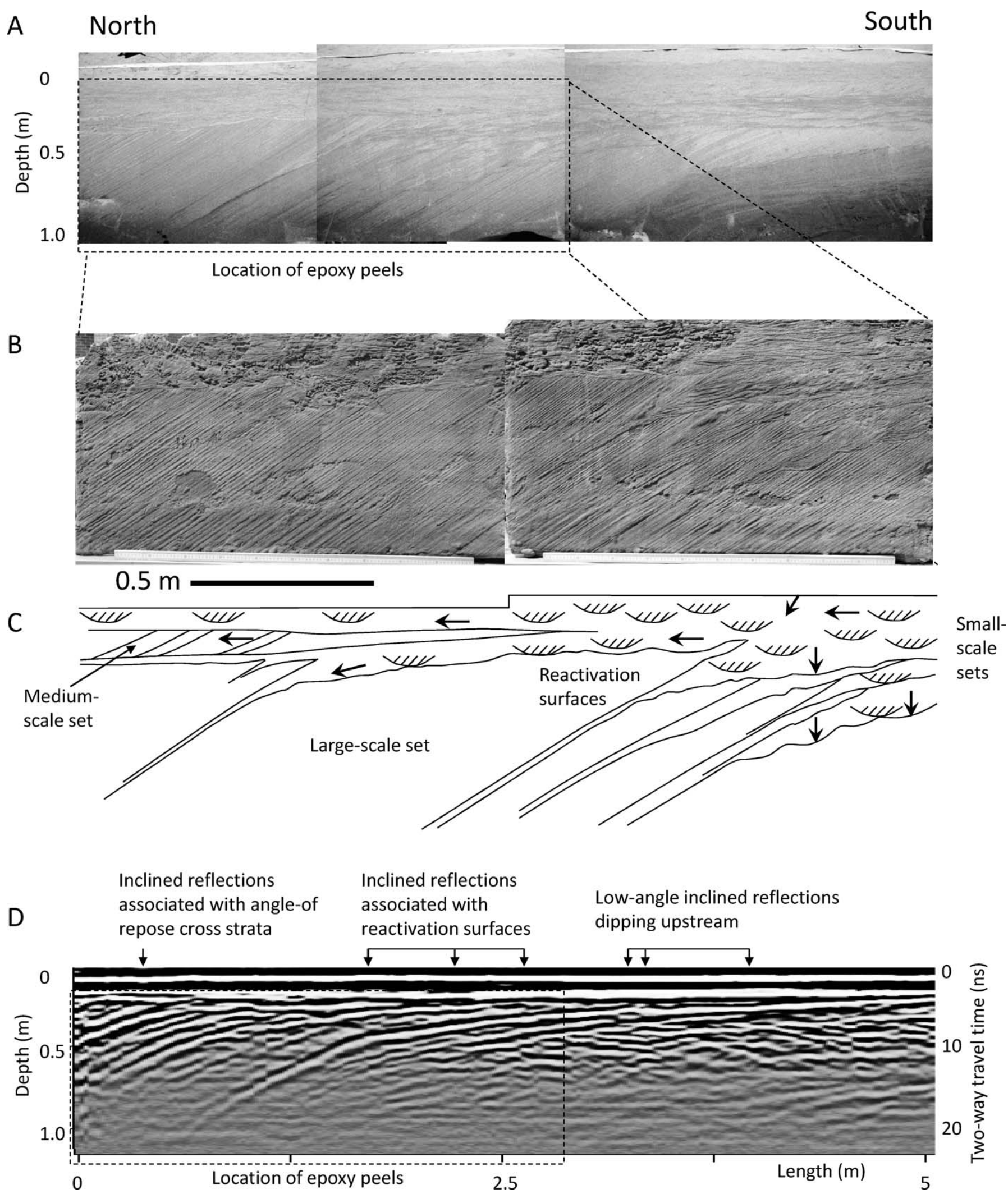

FIG. 14.-A) Trench, B) epoxy peels, C) interpretation, and D) GPR from the mid-channel bar in the Centre Angling (Location 4). Main river flow is into the profile, and main direction of aggradation is along the profile to the left. 
A

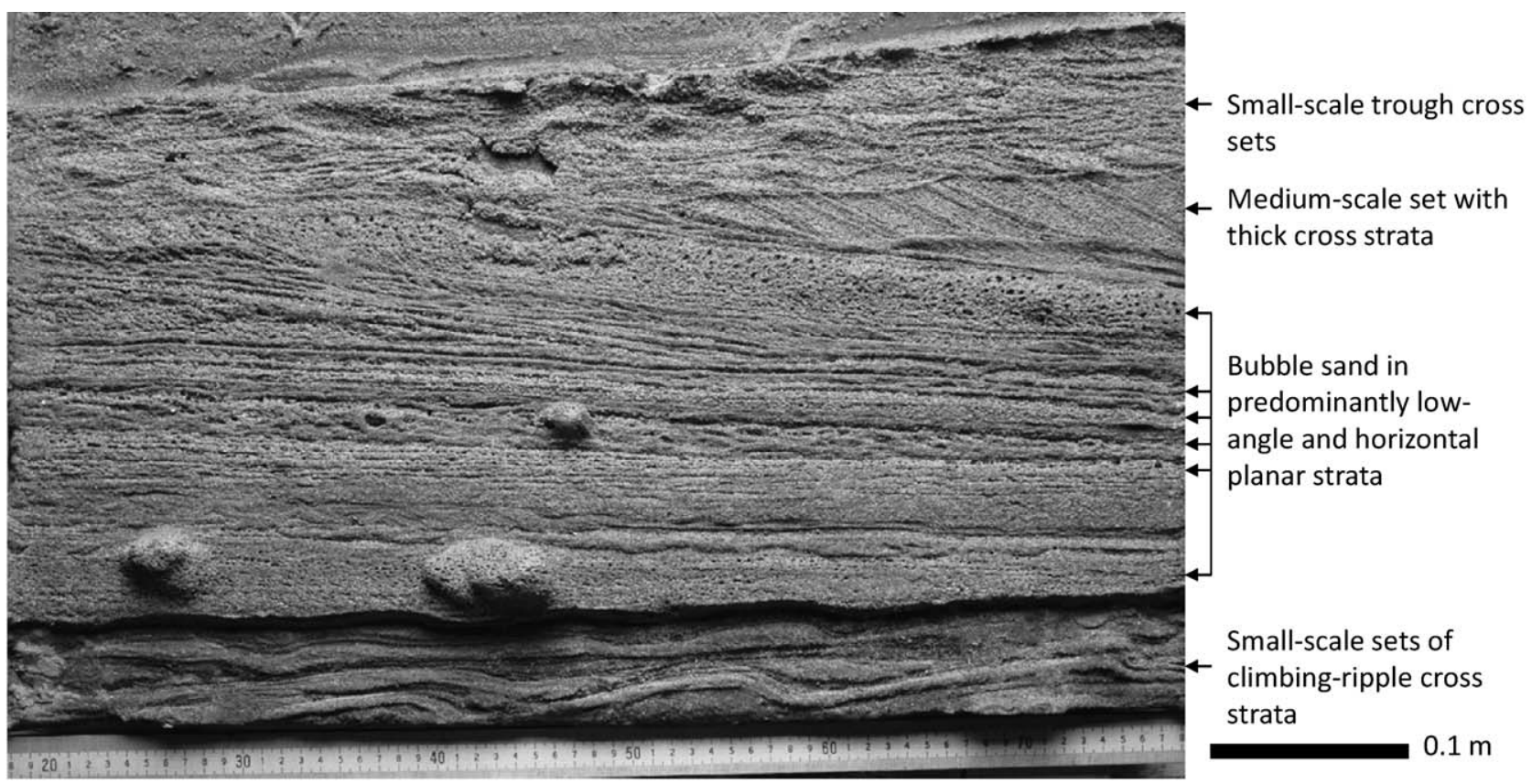

B

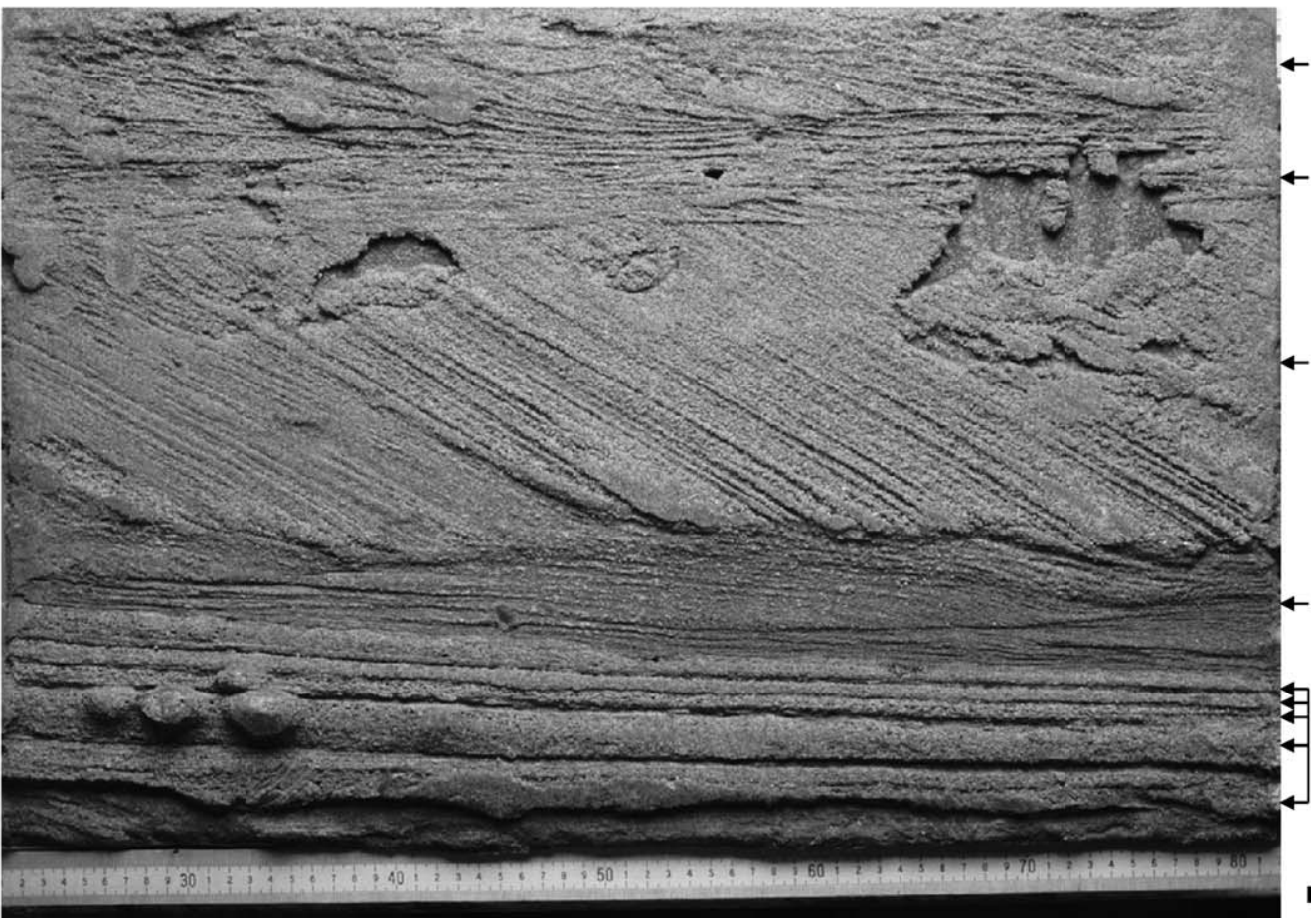

Down-climbing small-scale cross sets in a mediumscale cross set

Small-scale cross sets

Large-scale unit-bar cross set

Trough deposits: low-angle strata and small-scale cross sets

Bubble sand in predominantly lowangle and horizontal planar strata

FIG. 15.-Epoxy peels from deposits in a cross-bar channel at location 5 showing several layers of bubble sand and interbedded fine- and coarser-grained layers. Main river flow is from left to right and the profiles are oriented in the downstream direction.

place of the cross strata. The reflections that dip in the upstream direction are not caused by real structures (Fig. 14), but are limbs of refraction hyperbolae from locations elsewhere in the subsurface. The lack of structures of sufficient size and contrast in large-scale sets can thus result in a "void" in which reflections from elsewhere in the subsurface may dominate the amplitude pattern.

\section{UNIT-BAR TROUGHS AND EPHEMERAL CROSS-BAR CHANNELS}

\section{Location 5}

A trench dug in 2006 near locations 1 and 2 revealed outstanding examples of unit-bar trough deposits (Fig. 15). The orientation of the trough was approximately in a cross-stream direction. The trough 
deposits contained low-angle and horizontal strata: (i) fine-grained planar laminae attributed to lower-stage plane beds, (ii) small-scale crosslaminated sets attributed to ripples and climbing ripples, (iii) coarsergrained planar laminae attributed to bedload sheets formed in upperstage plane-bed conditions, (iv) some gravel that may represent a lag deposit, and (v) medium-scale low-angle cross-sets that could be attributed to antidunes. The internal structures of several of the coarser layers were poorly visible because of the presence of bubble sand.

\section{Interpretation}

The troughs of unit bars may act as ephemeral cross-bar channels during low flow stages where the troughs steer the flow across a compound bar. The lag deposits, antidunes, and upper-stage plane-bed conditions indicate high flow velocities. Indeed, standing waves and antidunes were commonly observed during rising and falling flow stages because locally high water-surface slopes generate high-velocity shallow flows through topographically lower areas such as cross-bar channels The occurrence of shallow high-energy flows depends on the vertical elevation and cross-bar water-surface gradients. Recurring emergence and rapid inundation cause entrapment of air in sand and hence the formation of bubble sand. Frequent and fairly rapid changes in flow stage caused by upstream dam releases explain the common occurrence of bubble sand in the deposits of the South Saskatchewan River. The alternation of such high-energy deposits with fine-grained lower-stage plane-bed deposits and ripple sets emphasizes the large changes in flow velocity and direction that occur in the unit-bar troughs as a result of changes in stage. Thus, both the foresets of the unit bars (reactivation surfaces) and the trough deposits (adjacent and alternating high- and low-energy deposits) are strongly affected by flow unsteadiness.

\section{OVERBANK SPLAY DEPOSIT}

\section{Location 6}

A bar-shaped overbank splay deposit formed during an individual flood of the South Saskatchewan River in 2005 was investigated shortly after the flood occurred. The splay was approximately $0.7 \mathrm{~m}$ high (Fig. 16). Eolian strata were actively formed on the lee slope of the splay during the investigation. The subaqueous overbank splay deposit thus continued to migrate as a subaerial bedform.

\section{Internal Structures}

The part of the deposit closest to the river (west) shows small-scale trough cross stratification (Fig. 16B, C). The small-scale sets indicate a dominant down-river flow direction and are formed by ripples moving down-river on the back and side of the unit bar. The small-scale set change laterally into a large-scale set of tangential cross strata that are 2.1 $( \pm 0.8) \mathrm{mm}$ thick (Figs. 6G, 16B, D). The lower part of the deposit is made up of obliquely climbing regressive ripples. These are interpreted as being formed by a combination of the return-flow current of the separated flow in the lee of the bedform and an along-slope component of the current on the floodplain. The large-scale cross strata change laterally from tangential, millimeter-thick cross strata to angular, centimeter-thick cross strata (Fig. 16E). The thick cross strata are $19( \pm 3.5) \mathrm{mm}$ thick on average (Fig. 6I), are delineated with distinct fine-grained drapes, and have internal strata associated with grainflows that are $5.5( \pm 1.5) \mathrm{mm}$ thick (Fig. $6 \mathrm{H}$ ). The average cross-sectional area of the thick cross strata is $1900( \pm 5000) \mathrm{mm}^{2}$, which is an order of magnitude larger than the ripples measured in the area, but matches realistic cross-sectional areas of dunes with approximate heights of $0.12 \mathrm{~m}$ and lengths of $1.6 \mathrm{~m}$. Moreover, the cross-sectional area of the cross strata associated with superimposed dunes changes in a downstream direction (Fig. 16G). Most of the thick cross strata have an internal coarsening-outward stratification superimposed on the layering associated with grainflows. This superimposed sorting pattern within the thick cross strata is associated with a fining-upward sorting within the formative superimposed dunes. The thick cross strata change abruptly into thick $(\sim 0.1 \mathrm{~m})$ angle-ofrepose cross strata of dry sand which continued to form on the lee slope by variations in eolian transport rates and transported grain size. The eolian cross strata vary in cohesion as a result of differences in water content, with some strata having too little cohesion to allow trenching (Fig. 16F)

\section{Interpretation}

The morphology of the splay deposit was identical to unit bars and is therefore interpreted as such. The finer-grained ripple sets in its bottomsets are consistent with a subaqueous origin and deceleration of the flow in the lee of the unit bar. The changes in the character of the cross strata in the large-scale set represent consecutive stages in its development. The millimeter-thick cross strata are associated with grainfall and strong modification of grainfall and grainflows by turbulence (Reesink and Bridge 2009). The tangential shape and the limited thickness cannot be formed by grainflows. Although superimposed bedforms (ripples or bedload sheets) may have been present on the unit bar, no diagnostic criteria were visible in the peels or in the trench face. The reduced visibility or loss of a pre-sorting pattern is consistent with an interpretation of high grainfall rates and redistribution on the lee slope by turbulence, although these processes do not automatically rule out the presence of pre-sorting patterns. The change to thick cross strata is caused by the development of superimposed dunes that gradually increase in height and that have vertical fining-upward grain-size sorting. The variation in cross-sectional area of the thick cross strata is large and cannot be explained by a change in the height of the unit bar during its formation. Moreover, changes in the cross-sectional area of the superimposed dunes are expected to be common because dune sizes are proportional to the water depth. The unit bar continues as a subaerial bedform after being emerged. Change in dune size recorded by the cross strata emphasizes the role of subaerial sediment transport in sandy river systems.

\section{Ground-Penetrating Radar (GPR)}

The downstream change in sedimentary structures was visible in the $900 \mathrm{MHz}$ GPR image (Fig. 16A). The low-angle surfaces composed of small-scale trough cross-stratified sets were represented by low-angle inclined reflections with smaller structures in between the low-angle reflections. The thin, tangential cross strata and the thick, angular cross strata formed by superimposed dunes were represented a limited number of low-amplitude inclined reflections in a set that is overall low in amplitude. The limited contrast and thickness of the strata explains the low amplitude of this set. Positive interference of minor reflections results in a low-amplitude and inconsistent appearance of inclined reflections. Conversely, the very thick $(\sim 0.1 \mathrm{~m})$ eolian cross strata are represented by high-amplitude inclined reflections. The much better visibility of the eolian cross strata in the GPR images is attributed to the larger thickness and differences in water content of successive eolian cross strata.

\section{DISCUSSION}

Detailed descriptions of cross strata and sets from trenches, epoxy peels, and GPR provide a wealth of information on the sediment and fluid dynamics that form river-channel deposits. The analyses presented in this study reveal various relationships between sedimentary structures and different combinations of bedform types and geometries, and hence an association of sedimentary structures with both the geomorphology of 


\section{West}

East

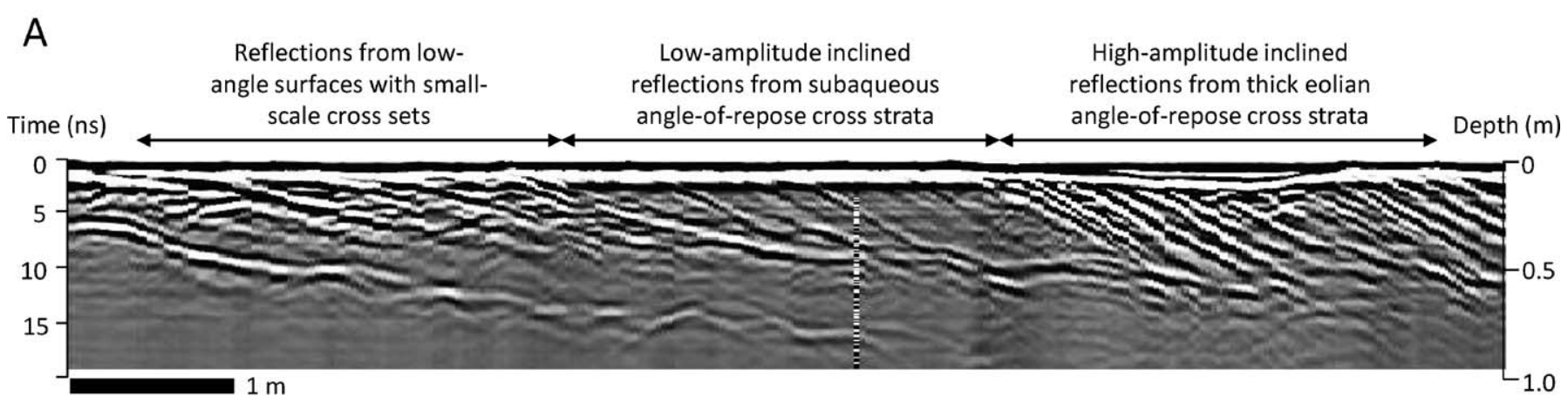

B

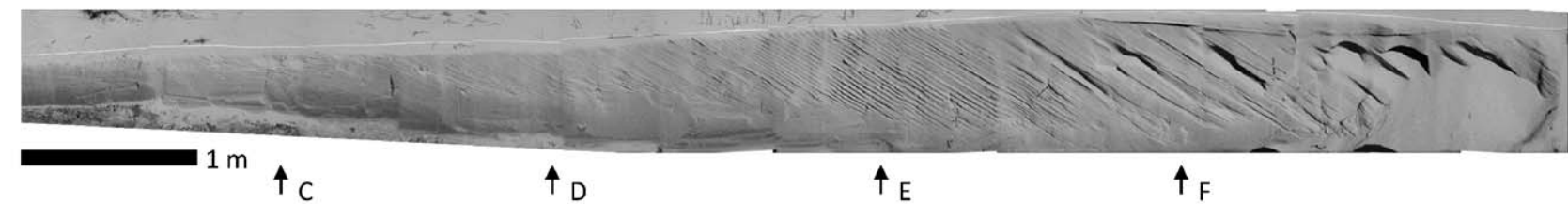

C

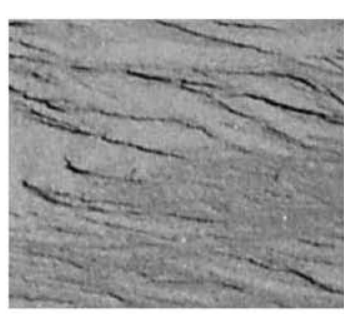

$0.1 \mathrm{~m}$

D

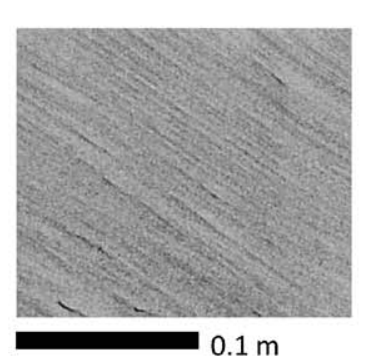

$\mathrm{E}$

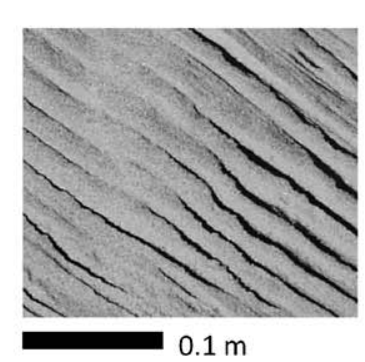

$\mathrm{F}$

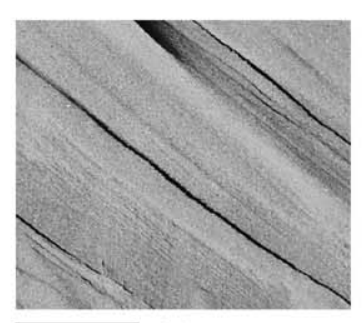

G

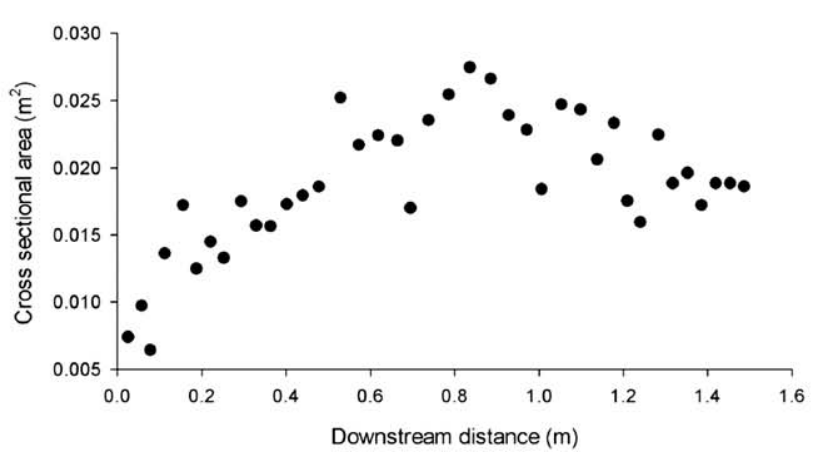

FIG. 16.-A) GPR image and B) photomosaic of a trench dug through the overbank splay deposit at location 6. Details of the sedimentary structures: C) small-scale trough cross stratification; D) very thin tangential cross strata; E) thick cross strata associated with superimposed dunes; and $\mathbf{F})$ very thick $(\sim 0.1 \mathrm{~m})$ eolian cross strata. G) Downstream change in the thickness of cross strata associated with superimposed bedforms. Note that $0.008 \mathrm{~m}^{2}$ is the largest cross sectional area measured for ripples in the area.

the channel and flow unsteadiness (Fig. 17). Because of its highly detailed nature, this process-based investigation does not provide a proportional structural composition of the South Saskatchewan River, but it illustrates the dependence of sedimentary structures on their unique history of formative flow and sediment transport conditions. Although a history of flow unsteadiness can be recorded as a grain-size sorting pattern (e.g., fine-grained drapes formed in still water), changes in formative stage are recorded primarily through changes in superimposed bedform type and size.

\section{The Composition of Unit-Bar Deposits}

The analyses show that the composition of unit bars can be subdivided into three Gilbert-style categories: topsets formed by bedforms on the back of the unit bars, foresets formed by deposition on the lee slope, and bottomsets formed in the bar trough (Fig. 17, cross sections A-F). The formation of these classes on respectively the bar top, the bar lee-slope and the bar trough are each associated with characteristic flow and sediment dynamics. The observations of the foresets and trough deposits 


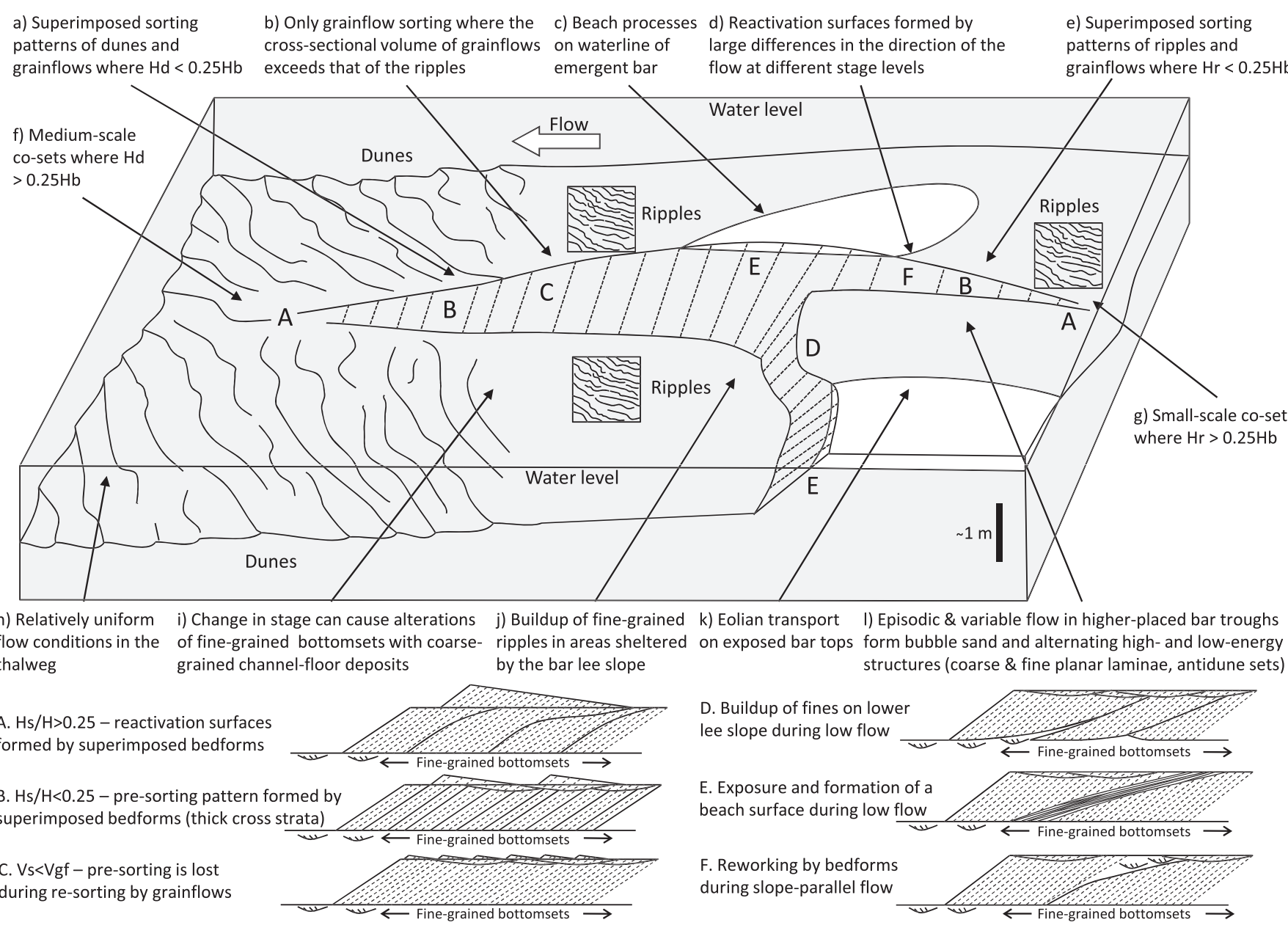

FIG. 17.-3D conceptual model of a sandy river in which local geomorphology and different combinations of host and superimposed bedforms control the depositional processes and the resultant diversity of cross-stratified sets.

from this study are discussed below in the context of this conceptual model. The analyses in this study are based primarily on the interpretation of epoxy peels, because these provide more detail on sorting patterns and stratal thicknesses than other methods and because they have a higher preservation potential relative to the topsets.

\section{Foresets: Angle-of-Repose Cross Strata}

Measurements and approximations of bedform sizes support the proposition that the separated-flow vortices of superimposed bedforms with heights below $\sim 0.25 \%$ of their host bedform heights are too weak to cause reduction of the host lee slope (Reesink and Bridge 2007, 2009). Small superimposed bedforms do generate a pre-sorting pattern (Smith 1972; Rust 1984) that is superimposed on re-sorting during deposition on the lee slope (Fig. 17B, a, e; Jopling 1965; Allen 1982; Kleinhans 2004). Either of these sorting patterns can dominate the other and render it unrecognizable (Fig. 17C, b). Identification of the sorting pattern associated with superimposed bedforms relied on identification of: (i) fine-grained drapes formed by a relative increase in settling from suspension during the passage of the superimposed bedform trough; (ii) the larger thickness of such strata in comparison to stratification formed by grainflows in the same sediment and ideally found within the largerscale pre-sorting pattern; (iii) the regular recurrence of these strata as a consequence of regularity of trains of bedforms passing over a brink point, (iv) connections of the fine-grained drapes to the bottomsets, the partial reactivation surfaces, and the topsets (Fig. 2). These criteria are valid for pre-sorting generated by dunes as well as ripples (Fig. 17B, a, e), and their distinction therefore relies on their along-stream cross-sectional area (Equation 1). Re-sorting during deposition on the host lee slope poses a limit to the minimum volume that is required to generate a visible pre-sorting pattern. For example, ripple pre-sorting patterns are difficult or impossible to identify where the pre-sorting pattern contains less than double the volume of re-sorting by grainflows (e.g., location 1, Fig. 5A). With maximum cross-sectional areas of ripples of approximately $3500 \mathrm{~mm}^{2}$ and grainflow thicknesses of approximately $5 \mathrm{~mm}$, this implies that ripple pre-sorting is unlikely to be identifiable in sets that exceed $0.35 \mathrm{~m}$ in height (Fig. 17 b). Pre-sorting can also be lost when the lee slope is reworked by the separated flow in the lee of the bedform or when deposition is rapid and significantly affected by turbulence (e.g., tangential strata at location 6). The cross-sectional areas, lateral extents, and internal sorting patterns of fully preserved cross strata generated by superimposed bedforms equal that of their superimposed formative bedforms. The cross-stream and plan-view shapes of the cross strata are controlled by the cross-stream and plan-view shapes of the host lee slope (see the excellent overview by Rubin 1987). These relationships provide powerful tools for the interpretation of formative bedforms from the sedimentary record, and hence interpretations of the formative flow conditions. For example, where the cross-sectional area of the formative bedforms can be assumed - which is reasonable for ripples because they have limited and regular cross-sectional areas-the proportion of the host 
bedform that has remained preserved can be reconstructed (e.g., locations 1 and 2). Likewise, where the height of the host bedform can be approximated or assumed steady, the change in cross-stratal volumes can be used to represent the change in superimposed bedform size (e.g., location 6). Because the formation of cross strata by superimposed bedforms is constrained by the heights of the host and superimposed bedforms, their presence is indicative of a limited set of conditions (Fig. 17). Ripple-generated cross strata are expected to be most abundant in shallow water where bars are low and shear stresses are limited (Fig. 17 e). Dune-generated cross strata are expected to be more common (Fig. 17 a), yet both types are unlikely to occur near the base of the channel where bar heights are low and dunes are large (Fig. 17 f; see also further down).

\section{Foresets: Inclined Co-Sets}

The data support the proposition that large superimposed bedforms $(H s / H>0.25$; Fig. 17 A, f, g) reduce the host lee slope and generate reactivation surfaces (Reesink and Bridge 2007, 2009). However, systematic research is needed to properly delineate the responsible fluid and sediment processes for a representative range of conditions before we can reliably interpret the hydraulic significance of inclined dune co-sets (Banks 1973; Allen 1974; Haszeldine 1982; Rubin and Hunter 1982; Hunter and Rubin 1983; Rust and Jones 1987; Martinius et al. 2002). For example, little is known about the effect of oblique-downstream migration of superimposed bedforms on the formative sediment and fluid dynamics and the preservation potential. Although their formation and geometry of inclined co-sets is at least partially dependent on the erosive nature of the separated flow in the lee of the downslope-migrating bedforms, the behavior of (interacting) separated flow patterns (Fernandez et al. 2006) within a larger-scale non-uniform flow is not known. Moreover, bedform superimposition is both caused and affected by flow unsteadiness (Allen and Collinson 1974; Allen and Friend 1976; Allen 1982; Ten Brinke et al. 1999; Kleinhans 2002; Leclair 2002; Paarlberg et al. 2006; Paarlberg et al. 2007; 2009; Paarlberg et al. 2010). Inclined sets do provide useful information on the sedimentary dynamics despite these gaps in our understanding. The structures of inclined sets that can be traced into the topsets in location 2 suggest that the proportion of a set that remains preserved increases significantly where dunes overtake a bar lee slope. This matches observations of decreasing heights, and hence locally increased sediment flux to the bed, of superimposed dunes migrating down the lee slope of larger dunes (Pretious and Blench 1951; Rubin and McCulloch 1980; Rubin and Hunter 1982; Amsler and Garcia 1997; Parsons et al. 2005). The decrease in heights of the down-climbing bedforms indicates a systematic flux of sediment to the host slope and hence a systematic increase in set thickness. Such increased preservation occurs in locations of distinct non-uniform flow, for which the existing models of set-preservation were not developed or tested (Paola and Borgman 1991; Bridge 1997; Leclair and Bridge 2001). The area between successive reactivation surfaces matches the area of the formative superimposed bedform where complete overtaking took place and can therefore be used to approximate sizes of the formative superimposed bedforms (e.g., location 3; Rubin and Hunter 1982). The height ratio between host bedforms and superimposed bedforms at which reactivation surfaces start to form is a useful general rule and appears to work for host dunes and host bars (Reesink and Bridge 2009). Because dunes scale to the water depth, the reduction of bars and the formation of co-sets should increase with depth (Fig. 17 f; also further below).

\section{Foresets: Reactivation Surfaces}

Reactivation surfaces are commonly lined with fine-grained material that forms baffles to interstitial flow through fluvial reservoirs and aquifers; they are erosional and low-deposition breaks in the development of bedforms and hence provide key evidence on temporal development of bedforms, and they generate GPR reflections that delineate and dissect the large-scale depositional units that are often treated as elementary the building blocks of channel deposits (overviews in Miall 1996; Bridge 2003). This study shows that an origin from flow unsteadiness is indicated by an irregular recurrence, a thickening of the bottomsets at the toe of the slope (Fig. 17D, j), the lack of upstream continuation of the inclined set into the topsets (location 2; McCabe and Jones 1977), and the association with structures that indicate changes in flow stage (Fig. 17E, F, c, d). The buildup of a wedge of sediment at the toe of the slope (Fig. 17D; location 3 ) is attributed to the larger length of time involved in flow-unsteadiness (here: daily) as opposed to the passage of superimposed dunes (here maximum in the order of 2-4 hours). Settling of sediment from suspension takes time and is unlikely to be significant during the relatively rapid passage of a superimposed dune. Changes in flow stage were expressed in variable sorting patterns in the cross strata (location 1), the presence of beach deposits (Fig. 17E; location 2), and changes in flow direction indicated by trough-shaped sets (Fig. 17F; locations 1 and 4; Collinson 1970; Collinson et al. 2006). However, not all floods left a visible mark in the sedimentary record (e.g., location 3). Concave-convex geometries of reactivation surfaces formed by large superimposed bedforms and continuation of inclined sets into upstream topsets (Fig. 17 A; cf. McCabe and Jones 1977) was found in only a limited number of reactivation surfaces. Interpretation of reactivation surfaces relies on multiple structural characteristics because most characteristics described here can be the result of both morphological and temporal change in the river. The abundance of different sizes and shapes of reactivation surfaces in the present study can be attributed to the presence of the upstream dam and the sandy braided morphology of the South Saskatchewan. Exposed unit bars are ubiquitous in other river systems, meandering and braided alike, such that the suggestion that unit bars commonly persist though multiple high-water events appears to be valid in general, albeit presently not quantified. The abundance and vertical placement of reactivation surfaces in unit bars may well be used to interpret a river's formative flow regime - a characteristic that can be representative for a considerable reach and hence outcrop-subsurface comparisons of partially exposed depositional systems.

\section{Unit-Bar Bottomsets and Trough-Deposits}

Unit-bar bottomsets are characteristically composed of fine-grained ripple sets, which contrast with the coarser-grained bar foresets (Fig. 17A-F). Indeed, deposition at the base of unit-bar slopes is characterized by settling of fine-grained material in the flow deceleration zone directly downstream of the bar lee slope (Fig. 17 i, j; Jopling 1961; Boersma et al. 1968; Reesink and Bridge 2009). It is suggested here that bar troughs do not behave identically to dune troughs: the turbulence and shear stresses of separated-flow vortices of most bars are relatively weak and unlikely to be responsible for rapid scour of the troughs on their own. Rather, the gradient and direction of sediment transport generated by the bars' separated flows and steering of (channelized) flow through the bar troughs and around the strongly three-dimensionally shaped bars are likely to play a dominant role in the formation of bar troughs. Bar-trough deposits are more broadly defined here to include channel-floor deposits as opposed to fine-grained unit-bar bottomsets formed near the bar slope. Where unit bars stack on top of one another, the channel floor associated with the upper bar is also the topset of the lower bar. Because bar troughs act as (ephemeral) channels during low flow stages (Fig. 17 1), the finegrained bottomsets are commonly underlain and interwoven with channel-floor deposits such as channel lags and coarser-grained dune sets (Fig. 17I; locations 2, 3, and 5). Such variability in the bottomsets forms under different flow conditions and relates primarily to flow unsteadiness. Bubble sand formed in bar-trough deposits (location 2 and 5 ) indicates that resubmergence of exposed troughs can occur relatively 
rapidly. The shallow, fast flows that follow the largest gradients over bar surfaces during resubmergence are also commonly observed to generate upper-stage plane beds, antidunes, and small hydraulic jumps. Coarsegrained low-angle strata and planar laminae found in bar-trough deposits (location 5) are indicative of such high-energy conditions. Because these conditions and structures are associated with rapid shallow flows, they are characteristic for bar troughs that act as ephemeral channels in the upper part of the channel deposits. The composition and heterogeneity in bar-trough deposits is thus dependent on both flow unsteadiness, the shape of the trough, and the vertical position in a channel.

\section{Expected Changes in Structural Composition with Depth and Stage Variability}

The trenches on which this study is based are located in the upper, exposed parts of the channel deposits. The nature and abundance of the investigated structures clearly depends to some degree on the vertical position in the channel. The higher parts of channel deposits are exposed for longer periods of time and experience larger differences in stage height in comparison to the thalweg (Fig. $17 \mathrm{c}, \mathrm{d}, \mathrm{k}, \mathrm{l}$ ). The association of structures with specific formative processes allows a number of predictions to be made about the vertical variability in structures within channel deposits.

\section{Vertical Change in Structural Composition}

Ripples are known to be more common in the upper parts of the channel where shear stresses are lower and where flow is mostly hydraulically smooth (Fig. 17 e, g). Pre-sorting patterns generated by superimposed ripples on relatively low bars ( $H$ less than approximately $0.35 \mathrm{~m}$ ) can therefore be expected to be most common the upper parts of the channel deposits. Regular pre-sorting patterns observed in the upper channel deposits in larger slopes ( $H$ less than approximately $0.35 \mathrm{~m}$; likely too large for ripple-pre-sorting patterns) are most likely to be the product of dunes present on the bar tops during floods. Irregular patterns on larger slopes are likely due to changes in the size of the transported sediment and in response to variable discharge. As opposed to ripples, dunes are expected to be common in the deeper parts of the thalweg where shear stresses are higher and flow is dominantly hydraulically rough (Fig. $17 \mathrm{f}, \mathrm{h}$ ). Bars nearer the thalweg have slopes and tops lower in the channel and are therefore more likely to have dunes superimposed on them (Fig. 17 a, f). Dunes scale to the water depth and therefore generally increase in height with depth. Bar heights are defined by their base and the bar top and thus decrease in height when they are located deeper in the channel. As a simple consequence of these systematic changes in dune and bar heights with depth, the chance of systematic reduction of a bar slope by superimposed dunes (threshold $H s / H \sim 0.25$ ) and the formation of inclined co-sets increases towards the base of the channel. This variability should systematically change the composition of bar deposits along the vertical. Flow deceleration in the lee of bars and associated settling of fine-grained sediment is limited where bar heights are low and water depths are large. The delineation of bar deposits by fine-grained bottomsets is therefore expected to be less pronounced in the lower parts of the channel deposits. Such poor delineation of individual bar deposits and the abundance of dune co-sets may hinder the recognition of bar deposits in lower channel deposits, especially in cores.

\section{Stage Dependency of Processes and Deposition}

The direction and velocity of the flow around bars changes with stage Changes in flow velocity and flow direction are much less pronounced in the thalweg as opposed to shallow flows around and over bar tops (Fig. $17 \mathrm{~d}$ ). The nature of the flow through bar troughs that act as ephemeral channels depends on their elevations, gradients, and contact with the main water-carrying channel (Fig. 17 1). The abundance of structures such as upper-stage plane beds and antidunes (observed in fast shallow flows through cross-bar channels), bubble sand (rapid inundation), and reactivation surfaces (e.g., along-slope flow) therefore depends on changes in stage as well as the vertical position. In addition to such changes in depositional processes, the locality of deposition also changes in response to flow unsteadiness (Bridge 1993b). This study provides examples of extreme cases of changes in locality of deposition in response to changes in stage such as periods without deposition (location 3 ). The nature of the hydrograph thus controls the composition and development of bars in addition to variables such as sediment size. The process-product relations presented in this study are the product of the comparison of flume studies (Reesink and Bridge 2007, 2009) with a limited number of optimally diverse, exposed bars and therefore cannot provide an overview or estimate of the abundance of specific structures of the South Saskatchewan River, nor as a function of stage variability and morphology in a wider sense. Conceptually, the variability in hydrographs varies between end members of stage variability. Rivers with a steady stage height should have distinct vertical preferences and trends in structural composition. Rivers with highly variable stage heights should have a limited vertical preference of structures. Structures such as bubble sand, reactivation surfaces, interbedded ripple sets, planar laminae, and antidunes should increase as stage variability changes more frequently. The range within which such structures are found in a vertical sequence should increase if the range in stage height is larger. Such dependency of structures on aspects of the hydrograph also implies that the structural composition of river deposits should respond to changes in climate and the drainage basin.

\section{Cross Strata and Unit-Bar Deposits in Ground-Penetrating Radar}

The GPR frequency used in this study is $900 \mathrm{MHz}$, which yielded a maximum vertical resolution in the order of $25 \mathrm{~mm}$ and a depth of penetration of 0.5 to $1 \mathrm{~m}$. Systematic comparisons of different GPR wavelengths for the South Saskatchewan River can be found in Woodward et al. (2003). Preferential attenuation of the higher frequencies has the potential to change the ability to monitor cross strata. The composition of the sediment that affects the ability of GPR to monitor the presence and composition of unit bars varies between areas with different boundary conditions such as different river systems, different river reaches, and different depths. Overall the ability of the GPR to monitor the internal composition of the unit-bar deposits (strata, reactivation surfaces, bottomsets) was limited in particular for the thinner unit bars $(>0.4 \mathrm{~m})$.

Thick and distinctly sorted larger-scale cross strata (locations 4 and 6 ) were associated with steeply inclined reflections. However, these reflections did not represent individual cross strata, of which there are many more, but are the product of positive interference of minor reflections (Neal 2004; Baker et al. 2007). The majority of the angle-ofrepose unit-bar cross strata did not generate distinct inclined reflections but were characteristically associated with low-amplitude areas in the GPR images. The lack of their visibility in the GPR images is attributed to their limited thickness and limited variation in grain size and electromagnetic properties. Unfortunately, low-amplitude zones in GPR images are nonspecific and can be the product of any well-sorted sedimentary facies (e.g., uniform ripple co-sets). The absence of clear reflections in GPR images therefore cannot be used to interpret the presence of specific structures. Locally, low-amplitude areas can be obscured by interference patterns and limbs of reflection hyperbolae from overlying structures and objects (e.g., location 4). Thus, absence of highangle reflections or a low-amplitude zone does not provide certainty that large-scale angle-of-repose cross strata are not present. GPR-based estimates of the abundance of bar-scale cross strata are therefore likely 
sensitive to underestimation. In contrast to cross strata, reactivation surfaces were generally identifiable in the GPR images. Their visibility in the GPR images is attributed to the larger spacing between reactivation surfaces and their larger contrast in sediment sorting. Because low-angle reflections within GPR images can be found dissecting both angle-ofrepose sets and stacks of horizontal sets, their presence is not indicative of surrounding structures or a specific origin. The term reactivation surface as used here describes a range of bounding surfaces with different origins (cf. Collinson 1970; Miall 1996; Collinson et al. 2006). Our understanding of the structural and spatial diversity of reactivation surfaces and their formative fluid and sediment dynamics remains incomplete at present. The strongest GPR reflections were generated by the interface between fine-grained bottomsets and relatively coarse-grained foresets. These high-amplitude basal reflections are laterally continuous, which suggests that the fine-grained bottomsets that underlie unit bars are laterally continuous. Multiples and reverberations of these strong reflections can obscure underlying structures. The presence of clay in the unit-bar bottomsets is likely to cause locally increased attenuation of the GPR signal. Although GPR can provide a rapid, nondestructive method of imaging the composition of river deposits (e.g., Bridge 2009), its use as a proxy for primary sedimentary structures lies on the limit of this technique's capabilities.

\section{CONCLUSIONS}

Comparison of detailed investigations of unit bars in the South Saskatchewan River and Centre Angling River, Saskatchewan, Canada, with recent experimental work reveals that cross-stratified sets can be used to constrain new and fundamental aspects of the formative flow and sediment dynamics. The relations between flow conditions, processes, and structures provide a basis to explain and predict systematic variability in structures within channel deposits.

- Single cross-stratified sets formed by unit bars commonly exist for timescales much longer than individual floods. The investigated barscale sets are therefore internally composed of cross strata with a range of geometries and grain-size sorting patterns that provide a record of the formative flow and sediment transport conditions.

- Flow unsteadiness causes changes in the grain-size sorting of the sediment in transport, but is primarily expressed as changes in the type, geometry, and direction of migration of the superimposed bedforms. Such changes are reflected in the geometry and sorting patterns of cross strata and reactivation surfaces.

- Superimposed bedforms with heights less than $25 \%$ of their hostbedform height do not reduce the host-bedform lee slope but cause recurring changes in the size of the sediment that is deposited on the host lee slope. These pre-sorting patterns and the geometries of the cross strata allow the interpretation of the type, relative height, alongstream cross-sectional area, lateral connectivity, and internal grainsize segregation of the formative superimposed bedforms, and the height and three-dimensional shape of the host bedform slope. This information can be used to constrain conditions of flow and sediment transport on the back of the host bedform.

- Where the along-stream cross-sectional area of the formative superimposed bedforms can be assumed, the sorting of cross strata can be used to establish the original height of the host bedform and hence the proportion of the original bedform height that is preserved. This analysis suggested that bedform preservation is enhanced in areas of flow deceleration. Where the height of the host bedform can be assumed, the sorting of cross strata can reveal changes in superimposed bedform size, hence changes in formative flow conditions.

- The bar sets were frequently intersected by low-angle reactivation surfaces formed by superimposed bedforms with heights exceeding $25 \%$ of their host-bedform height. The abundance of reactivation surfaces should increase with depth because bar thickness decreases with depth whereas dune thickness increases with depth.

- As opposed to reactivation surfaces formed by dunes superimposed on unit bars, reactivation surfaces associated with flow unsteadiness were associated with overlying smaller-scale structures and increased thickness of the bottomsets. In particular, lateral accretion on unit bars was characterized by alternations of angle-of-repose cross strata and reactivation surfaces with overlying smaller-scale trough cross strata or beach deposits.

- Bar troughs that are placed high in the channel acted as ephemeral channels and were frequently emerged and re-submerged during the daily changes in stage height. The deposits of these bar troughs were internally composed of planar and low-angle strata, and commonly converted to bubble sand. These effects of stage variability on the unit-bar deposits should be less common or absent in the deeper and continuously submerged parts of the channel.

- The $900 \mathrm{MHz}$ GPR images were dominated by reflections from finegrained set bases. Most reactivation surfaces could be observed in the radar images. Angle-of-repose cross strata were commonly too thin and well-sorted to generate visible reflections and were primarily represented by low-amplitude zones in between strong reflections that are formed by the bounding surfaces.

\section{ACKNOWLEDGMENTS}

The authors would like to thank the South Saskatchewan River project, in particular Jim Best, Phil Ashworth, Ian Lunt, Greg Sambrook Smith, Natalie Parker, and Chris Simpson. Partial funding for this project was provided by the Association for Canadian Studies in The Netherlands (ACSN) and the American Association of Petroleum Geologists (AAPG). The investigation of the mid-channel bar in the Centre Angling River was made possible by Sanneke van Asselen and Ingwer Bos. David Janesko contributed provided valuable help in the field. Reviews by Stuart Archer, Nigel Mountney, Gary Weissmann, and Paul McCarthy have been invaluable for the improvement of this paper.

\section{REFERENCES}

Alexander, J., Bridge, J.S., Cheel, R.J., and Leclair, S.F., 2001, Bedforms and associated sedimentary structures formed under supercritical water flows over

aggrading sand beds: Sedimentology, v. 48, p. 133-152.
AlLEN, J.R.L., 1974, Sedimentology of Old Red Sandstone (Silurodevonian) in Clee Hills area, Shropshire, England: Sedimentary Geology, v. 12, p. 73-167.

Allen, J.R.L., 1982, Sedimentary structures, their character and physical basis, Volume 2: Amsterdam, Elsevier Scientific Publishing Company, Developments in Sedimentology, v. 30B, 593 p.

Allen, J.R.L., 1983, Studies in fluviatile sedimentation-bars, bar-complexes and ALLEN, J.R.L., 1983, Studies in fluviatile sedimentation-bars, bar-complexes and
sandstone sheets (low-sinuosity braided streams) in the Brownstones (L-Devonian), Welsh Borders: Sedimentary Geology, v. 33, p. 237-293.

Allen, J.R.L., And Collinson, J.D., 1974, The superimposition and classification of dunes formed by unidirectional aqueous flows: Sedimentary Geology, v. 12, p. 169-178.

Allen, J.R.L., AND Friend, P.F., 1976, Relaxation time of dunes in decelerating aqueous flows: Geological Society of London, Journal, v. 132, p. 17-26.

AmSLER, M.L., and GaRCIA, M.H., 1997, Sand-dune geometry of large rivers during floods-Discussion: Journal of Hydraulic Engineering, v. 123, p. 582-585.

Ashworth, P.J., Sambrook Smith, G.H., Best, J.L., Bridge, J.S., Lane, S.N., Lunt, I.A., Reesink, A.J.H., Simpson, C.J., And Thomas, R.E., in press, Evolution and sedimentology of a sandy braided channel fill and its differentiation from compound bar deposits: Sedimentology.

BaKer, G.S., Jordan, T.E., AND PARDY, J., 2007, An introduction to ground penetrating radar (GPR), in Baker, G.S., and Jol, H.M., eds., Stratigraphic Analyses using GPR: Geological Society of America, Special Publication 432, p. 1-18.

BANKS, N.L., 1973, The origin and significance of some down-current dipping crossstratified sets: Journal of Sedimentary Petrology, v. 43, p. 423-427.

BEST, J.L., AND BRIDGE, J.S., 1992, The morphology and dynamics of low-amplitude bedwaves upon upper stage plane beds and the preservation of planar laminae: Sedimentology, v. 39, p. 737-752.

Best, J.L., Woodward, J., Ashworth, P., Sambrook Smith, G., and Simpson, C., 2006, Bar-top hollows: a new element in the architecture of sandy braided rivers: Sedimentary Geology, v. 190 , p. 241-255. 
Blodgett, R.H. AND Stanley, K.O., 1980, Stratification, bedforms, and discharge relations of the Platte braided river system, Nebraska: Journal of Sedimentary Petrology, v. 50, p. 139-148

Boersma, J.R., Van de Meene, E.A., and Tualsma, R.C., 1968, Intricated cross stratification due to interaction of a mega ripple with its leeside of backflow ripple (upper point bar deposits, Lower Rhine): Sedimentology, v. 11, p. 147-162.

Bouma, A.H., 1979, Methods for the Study of Sedimentary Structures: New York, Robert E. Krieging Publishing Co., 474 p.

BRIDGE, J.S., 1993a, Description and interpretation of fluvial deposits-a critical perspective: Sedimentology, v. 40, p. 801-810

BRIDGE, J.S., 1993b, The interaction between channel geometry, water flow, sediment transport and deposition in braided rivers, in Best, J.L., and Bristow, C.S., eds., Braided Rivers: Geological Society of London, Special Publication 75, p. 13-71.

BRIDGE, J.S., 1997, Thickness of sets of cross strata and planar strata as a function of formative bed-wave geometry and migration, and aggradation rate: Geology, v. 25, p 971-974.

BRIDGE, J.S., 2003, Rivers and Floodplains; Forms, Processes, and Sedimentary Record Oxford, U.K., Blackwell Publishing, 600 p.

BRIDGE, J.S., 2009, Advances in fluvial sedimentology using GPR, in Jol, H.M., ed. Ground Penetrating Radar; Theory and Applications: Amsterdam, Elsevier, p. 323-359.

Bridge, J.S., And Demicco, R.V., 2008, Earth Surface Processes, Landforms, and Sediment Deposits: Cambridge, U.K., Cambridge University Press, 830 p.

CANT, D.J., 1978, Bedforms and bar types in South Saskatchewan River: Journal of Sedimentary Petrology, v. 48, p. 1321-1330.

CANT, D J., AND WaLKER, R.G., 1978, Fluvial processes and facies sequences in the sandy braided South Saskatchewan River, Canada: Sedimentology, v. 25, p. 625-648.

Collinson, J.D., 1970, Bedforms of the Tana River, Norway: Geografiske Annaler, Series A: Physical Geography, v. 52, p. 31-56.

Collinson, J., Mountney, N., And Thompson, D., 2006, Sedimentary Structures: Harpenden, U.K., Terra Publishing, 292 p.

De Boer, P.L., 1979, Convolute lamination in modern sands of the estuary of the Oosterschelde, The Netherlands, formed as the result of entrapped air: Sedimentology, v. 26, p. 283-294.

De RaAf, J.F.M., Boersma, J.R., and Van Gelder, A., 1977, Wave-generated structures and sequences from a shallow marine succession, Lower Carboniferous, County Cork, Ireland: Sedimentology, v. 24, p. 451-483.

Ethridge, F.G., Skelly, R.L., AND BRISTow, C.S., 1999, Avulsion and crevassing in the sandy, braided Niobrara River: complex response to base-level rise and aggradation, in Smith, N.D., and Rogers, J., eds., Fluvial Sedimentology VI: Blackwell Publishing, p. 179-191.

FARRELL, K.M., 2001, Geomorphology, facies architecture, and high-resolution nonmarine sequence stratigraphy in avulsion deposits, Cumberland Marshes, Saskatchewan: Sedimentary Geology, v. 139, p. 93-150.

Federici, B., and Seminara, G., 2003, On the convective nature of bar instability: Journal of Fluid Mechanics, v. 487, p. 125-145.

Federici, B., and Seminara, G., 2006, Effect of suspended load on sand bar instability: Water Resources Research, v. 42, W07407, doi: 10.1029/2005WR004399.

Fernandez, R., Best, J., AND Lopez, F., 2006, Mean flow, turbulence structure, and bed form superimposition across the ripple-dune transition: Water Resources Research, v. 42 , p. $948-963$

HASZELDINE, R.S., 1982, Descending tabular cross-bed sets and bounding surfaces from a fluvial channel in the Upper Carboniferous of North-East England: Journal of Sedimentary Petrology, v. 53, p. 1233-1247.

Hickin, E.J., 1993, Fluvial facies models - a review of Canadian research: Progress in Physical Geography, v. 17, p. 205-222.

HunTer, R.E., AND Rubin, D.M., 1983, Interpreting cyclic cross-bedding, with an example from the Navajo Sandstone, in Brookfield, M.E., and Ahlbrandt, T.S., eds Aeolian Sediments and Processes: Amsterdam, Elsevier, p. 429-454

JACKSON, R.G., 1976, Large scale ripples of the Lower Wabash River: Sedimentology, v. 23 , p. $593-623$.

JoL, H.M., AND BRISTOw, C.S., 2003, GPR in sediments: advice on data collection, basic processing and interpretation, a good practice guide, in Bristow, C.S., and Jol, H.M. eds., Ground Penetrating Radar in Sediments: Geological Society of America, Specia Publication 211, p. 9-27.

Jopling, A.V., 1961, Origin of regressive ripples explained in terms of fluid-mechanic processes: U.S. Geological Survey, Professional Paper, 424D, p. 15-17.

JopLING, A.V., 1965, Laboratory study of the distribution of grain sizes in cross bedded deposits, in Middleton, G.V., ed., Primary Sedimentary Structures and Thei Hydrodynamic Interpretation: SEPM, Special Publication 12, p. 53-65.

KLEINHANS, M.G., 2002, Sorting out sand and gravel; sediment transport and deposition in sand-gravelbed rivers: Utrecht University: Utrecht, 293 p.

KLEINHAns, M.G., 2004, Sorting in grain flows at the lee side of dunes: Earth Science Reviews, v. 65, p. 75-102.

Knaapen, M.A.F., Hulscher, S.J.M.H., De Vriend, H.J., and Van Harten, A., 2001 Height and wavelength of alternate bars in rivers: modeling and laboratory experiments: Journal of Hydraulic Research, v. 39, p. 147-153.

Lane, S.N., Widdison, P.E., Thomas, R.E., Ashworth, P.J., Best, J.L., Lunt, I.A Smith, G.H.S., And Simpson, C.J., 2010, Quantification of braided river channe change using archival digital image analysis: Earth Surface Processes and Landforms, v. 35 , p. $971-985$.

LanzonI, S., 2000, Experiments on bar formation in a straight flume: 1. Uniform sediment: Water Resources Research, v. 36, p. 3337-3349.
LECLAIR, S.F., 2000, Preservation of cross strata due to migration of subaqueous dunes [Ph.D. Thesis]: Binghamton University: Binghamton, New York.

LECLAIR, S.F., 2002, Preservation of cross strata due to migration of subaqueous dunes: an experimental investigation: Sedimentology, v. 49, p. 1157-1180.

LeClair, S.F., AND Bridge, J.S., 2001, Quantitative interpretation of sedimentary structures formed by river dunes: Journal of Sedimentary Research, v. 71, p. 713-716.

LeClaiR, S.F., BRIDGE, J.S., AND WANG, F.Q., 1997, Preservation of cross-strata due to migration of subaqueous dunes over aggrading and non-aggrading beds: comparison of experimental data with theory: Geoscience Canada, v. 24, p. 55-66.

LeVEY, R.A., 1978, Bed form distribution and internal stratification of coarse grained point bars upper Congaree River, S.C., in Miall, A.D., ed., Fluvial Sedimentology: Calgary, Canadian Society of Petroleum Geologists, p. 105-127.

Lunt, I.A., Bridge, J.S., AND Tye, R.S., 2004, A quantitative, three-dimensional depositional model of gravelly braided rivers: Sedimentology, v. 51, p. 377-414

Martinius, A.W., Geel, C.R., And Arribas, J., 2002, Lithofacies characterization of fluvial sandstones from outcrop gamma-ray logs (Loranca Basin, Spain): the influence of provenance: Petroleum Geoscience, v. 8, p. 51-62.

McCABE, P.J., 1977, Deep distributary channels and graint bedforms in Upper Carboniferous of central Pennines, Northern England: Sedimentology, v. 24, p 271-290.

McCabe, P.J., AND Jones, C.M., 1977, Formation of reactivation surfaces within superimposed deltas and bedforms: Journal of Sedimentary Petrology, v. 47, p. $707-715$

McKee, E.D., And WeIR, G.W., 1953, Terminology for stratification and crossstratification in sedimentary rocks: Geological Society of America, Bulletin, v. 64, p. $381-90$

Miall, A.D., 1995, Description and interpretation of fluvial deposits-a critical perspective: Sedimentology, v. 42, p. 379-384.

Miall, A.D., 1996, The Geology of Fluvial Deposits; Sedimentary Facies, Basin Analysis and Petroleum Geology: Berlin, Springer-Verlag, 598 p.

NeAL, A., 2004, Ground-penetrating radar and its use in sedimentology: principles, problems and progress: Earth-Science Reviews, v. 66, p. 261-330.

Nicholas, A.P., 2010, Reduced-complexity modelling of free bar morphodynamics in alluvial channels: Journal of Geophysical Research, v. 115, F04021 doi: 10.1029/ 2010JF001774.

Paarlberg, A.J., Dohmen-Janssen, C.M., Hulscher, S.J.M.H., Van den berg, J., And Termes, A.P.P., 2006, Modelling morphodynamic evolution of river dunes, in Ferreira, R.M.L., Alves, C.T.L., Leal, G.A.B., and Cardoso, A.H., eds., River Flow 2006, Volumes 1 and 2: Proceedings and Monographs in Engineering, Water and Earth Sciences, Taylor and Francis: London, p. 969-978.

PaArlberg, A.J., Dohmen-Janssen, C.M., Hulscher, S.J.M.H. and Termes, P., 2007, A parameterization of flow separation over subaqueous dunes: Water Resources Research, v. 43, W12417.

Paarlberg, A.J., Dohmen-Janssen, C.M., Hulscher, S.J.M.H., and Termes, P., 2009, Modeling river dune evolution using a parameterization of flow separation: Journal of Geophysical Research, v. 114, (F01014), doi: 10.1029/2007JF000910.

Paarlberg, A.J., Dohmen-Janssen, C.M., Hulscher, S.J.M.H., Termes, P., and Schielen, R., 2010, Modelling the effect of time-dependent river dune evolution on bed roughness and stage: Earth Surface Processes and Landforms, v. 35, p. 1854-1866.

PaOla, C., and Borgman, L., 1991, Reconstructing random topography from preserved stratification: Sedimentology, v. 38 , p. 553-565

Parsons, D.R., Best, J.L., Orfeo, O., Hardy, R.J., Kostaschuk, R., and Lane, S.N., 2005, Morphology and flow fields of three-dimensional dunes, Rio Parana, Argentina: results from simultaneous multibeam echo sounding and acoustic Doppler curren profiling: Journal of Geophysical Research, v. 110, doi: 10.1029/2004JF000231.

Pettijohn, F.J., Potter, P.E., And Siever, R., 1987, Sand and Sandstone: New York, Springer-Verlag, $553 \mathrm{p}$.

Pretious, E.S., And Blench, T., 1951, Final report on special observations of bed movement in Lower Fraser River at Ladner Reach during 150 freshet and till jun 1951. Including Supplementary Report No. 1: Vancouver, B.C., National Research Council of Canada, Fraser River Model.

ReEsinK, A.J.H., AND BRIDGE, J.S., 2007, Influence of superimposed bedforms and flow unsteadiness on formation of cross strata in dunes and unit bars: Sedimentary Geology, v. 202, p. 281-296.

REESINK, A.J.H., AND BRIDGE, J.S., 2009, Influence of bedform superimposition and flow unsteadiness on the formation of cross strata in dunes and unit bars-Part 2 , further experiments: Sedimentary Geology, v. 222, p. 274-300

RøE, S.-L., and Hermansen, M., 1993, Processes and products of large, Late Precambrian sandy rivers in Northern Norway, in Marzo, M., and Puigdefabregas, C., eds., Alluvial Sedimentation: Oxford, U.K., Blackwell Scientific Publications, p. $151-166$

RuBIN, D.M., 1987, Cross-bedding, bedforms and paleo-currents: SEPM, Concepts in Sedimentology and Paleontology, no. 1, $187 \mathrm{p}$.

Rubin, D.M., AND HunTER, R.E., 1982, Bedform climbing in theory and nature: Sedimentology, v. 29, p. 121-138

Rubin, D.M., AND McCulloch, D.S., 1980, Single and superimposed bedforms-a synthesis of San Francisco Bay and flume observations: Sedimentary Geology, v. 26, p. 207-231.

Rust, B.R., 1984, Proximal braidplain deposits in the Middle Devonian Malbaie Formation of Eastern Gaspe, Quebec, Canada: Sedimentology, v. 31, p. 675-696. 
Rust, B.R., And Jones, B.G., 1987, The Hawkesbury Sandstone South of Sydney, Australia-Triassic analog for the depsit of a large braided river: Journal of Sedimentary Petrology, v. 57, p. 222-233.

Sambrook Smith, G.H., Ashworth, P.J., Best, J.L., Woodward, J., and Simpson, C.J., 2005, The morphology and facies of sandy braided rivers: some considerations of scale invariance, in Blum, M.D., Marriott, S.B., and Leclair, S.F., eds., Fluvial Sedimentology VII: International Association of Sedimentologists, Special Publication 35 , p. $145-158$

Sambrook Smith, G.H., Ashworth, P.J., Best, J.L., Woodward, J., and Simpson, C.J., 2006, The sedimentology and alluvial architecture of the sandy braided South Saskatchewan River, Canada: Sedimentology, v. 53, p. 413-434.

Sambrook Smith, G.H., Ashworth, P.J., Best, J.L., Lunt, I.A., Orfeo, O., and Parsons, D.R., 2009, The sedimentology and alluvial architecture of a large braid bar, Río Paraná, Argentina: Journal of Sedimentary Research, v. 79, p. 629-642.

Sambrook Smith, G.H., Best, J.L., Ashworth, P.J., Lane, S.N., Parker, N.O., Lunt, I.A., Thomas, R.E., And Simpson, C.J., 2010, Can we distinguish flood frequency an magnitude in the sedimentological record of rivers?: Geology, v. 38, p. 579-582.

Seminara, G., And Tubino, M., 1989, Alternate bars and meandering: free, forced and mixed interactions, in Ikeda, S., and Parker, G., eds., River Meandering: American Geophysical Union, Water Resource Monitoring, p. 276-320.

SMITH, N.D., 1972, Some sedimentological aspects of planar cross-stratification in a sandy braided river: Journal of Sedimentary Petrology, v. 42, p. 624-634

Smith, N.D., 1974, Sedimentology and bar formation in the upper Kicking Horse River: a braided outwash stream: Journal of Geology, v. 82, p. 205-223.
Smith, N.D., Slingerland, R.L., Perez-Arlucea, M., and Morozova, G.S., 1998, The 1870s avulsion of the Saskatchewan River: Canadian Journal of Earth Sciences, v. 35 p. $453-466$

Stockwell, J.W., And Cohen, J.K., 2008, The new SU User's Manual: Golden, CO, Colorado School of Mines.

Storms, J.E.A., Van Dam, R.L., And Leclair, S.F., 1999, Preservation of cross-sets due to migration of current ripples over aggrading and non-aggrading beds: comparison of experimental data with theory: Sedimentology, v. 46, p. 189-200.

Ten Brinke, W.B.M., Wilbers, A.W.E., and Wesseling, C., 1999, Dune growth, decay and migration rates during a large-magnitude flood at a sand and mixed sand-gravel bed in the Dutch Rhine river system: International Association of Sedimentologists, Special Publication 28, p. 15-32

Thоmas, R.E., 2006, Flow Processes and Channel Change in Sand-Bedded Braided Rivers [Ph.D. dissertation]: University of Leeds: Leeds, 295 p.

Tubino, M., Repetto, R., and Zolezzi, G., 1999, Free bars in rivers: Journal of Hydraulic Research, v. 37 , p. $759-75$

Williams, G.E., 1971, Flood deposits of the sand-bed ephemeral streams of Central Australia: Sedimentology, v. 17, p. 1-40.

Woodward, J., Simpson, C.J., Ashworth, P.J., Best, J.L., and Sambrook Smith, G.H., 2003, The use and application of GPR in sandy fluvial environments: methodological considerations, in Bristow, C.S., and Jol, H.M., eds., Ground Penetrating Radar in Sediments: Geological Society of London, p. 127-142.

Received 30 March 2010; accepted 16 June 2011 